\title{
Surgical Treatment of Gastroesophageal Reflux Disease
}

\author{
Filippo Tosato ${ }^{1}$, Salvatore Marano ${ }^{1}$, \\ Stefano Mattacchione ${ }^{1}$, Barbara Luongo ${ }^{1}$, \\ Giulia Paltrinieri ${ }^{1}$, Valentina Mingarelli ${ }^{1}$ \\ and Leoluca Vasapollo ${ }^{2}$ \\ ${ }^{1}$ Referral Center for the Surgical Treatment \\ of Gastroesophageal Reflux Diseases, \\ "Sapienza" University of Rome \\ ${ }^{2}$ Sandro Pertini Hospital, Rome \\ Italy
}

\section{Introduction}

Gastro-esophageal reflux disease (GERD) is "a condition which develops when the reflux of stomach contents causes troublesome symptoms (i.e., at least two heartburn episodes per week) and/or complications" (Vakil et al 2006) and represents one of the fastest growing disease affecting the alimentary tract. Recently studies on the epidemiology of GERD demonstrating that GERD is a highly prevalent disorder with $10-20 \%$ of individuals affected in western civilization (Dent et al 2005). When GERD is defined as twice weekly reflux over several months, $10-20 \%$ of individuals in Western civilization are affected, which is significantly higher than in Asian population (5\%) (Bonatti et al 2008). In a large prospective American cohort study is reported that $25 \%$ of investigated individuals experienced nocturnal reflux symptoms (Fass et al 2005). A recent population-based study demonstrated the prevalence of reflux symptoms to be $44 \%$ with $24 \%$ of individuals experiencing symptoms for two days or more per week. The prevalence of oesophagitis and Barrett's oesophagus was $12 \%$ and $1.3 \%$ respectively, irrespective of symptoms (Zagari et al 2008).Thirty-three per cent of individuals with oesophagitis and $46 \%$ with Barrett's oesophagus were asymptomatic. Severe GERD can lead to potentially avoidable complications including severe oesophagitis with scarring and stricture formation, Barrett's esophagus and adenocarcinoma.When symptoms become frequent and severe enough to require regular medication, there is a significant impact on quality of life (Ware et al 1992).(QOL)

\section{Pathophysiology}

GERD results from failure of the reflux barrier. This barrier has three components: (1) an intra-abdominal esophagus of adequate length, (2) an extrinsic sphincter, the esophageal hiatus, and (3) an intrinsic sphincter, the lower esophageal sphincter (Bloom et al 2009). 
Relaxation of the LES and crura are normal physiological processes occurring during swallowing and also during gas venting. Relaxations not initiated by a swallow are known as transient lower esophageal relaxations (TLESRs). Abnormal TLESRs have a greater crosssectional area at the gastro-oesophageal junction resulting in the reflux of gastric fluid in addition to gas. TLESRs probably account for $90 \%$ of reflux episodes. The TLESR reflex is initiated by tension receptors in the stomach and mediated by a vagovagal pathway via the brainstem leading to simultaneous relaxation of the crura, LES and inhibition of peristalsis (Pandolfino et al 2003). These responses are inhibited by gammaaminobutyric acid-B (GABA-B) receptor agonists, and thus may constitute a future therapeutic target. Hiatus hernias appear to increase the magnitude of reflux during TLESRs. Transient lower oesophageal relaxations appear to be less significant in more severe reflux esophagitis. A hypotensive LES, which allows high pressure gradients across the diaphragm, is probably responsible for more severe esophagitis (Barham et al 1995). Reflux occurs more frequently when the pressure in the LES is $<10 \mathrm{~mm} \mathrm{Hg}$, and free reflux only occursif the LES pressure is <4 mm Hg (Kahrilas et al 1986; Dodds et al 1982). Factors which relax the LES, such as caffeine, fat, smoking, drugs (calcium channel antagonists and nitrates) and gastric distention, will increase the likelihood of reflux. The association of increased body mass index and GERD remains unclear (Hampel et al 2005; Pandolfino et al 2006). A recent study failed to demonstrate an increased risk of reflux symptoms or esophagitis in obese individuals. Acid in the distal oesophagus has been shown to be neutralised by saliva. Therefore any processes reducing saliva production results in a delay in acid neutralisation. Nocturnal reflux episodes are prolonged due to depressed salivation. Acid is cleared by oesophageal peristalsis. Therefore impaired distal esophageal peristalsis results in prolonged acid exposure to acid reflux episodes. This is apparent in both hiatus hernias and ulcerative oesophagitis where there is peristaltic dysfunction (Kahrilas et al 2006, Johnson et al 1980).

\section{Simptomatology}

Typical GERD symptoms - heartburn and regurgitation-reflect dysfunction of the reflux barrier.

Dysphagia is a third, less specific, GERD symptom. It may be caused by GERD itself or stricture complicating GERD. GERD-related dysphagia must be differentiated from functional and mechanical dysphagia resulting from multiple other diseases that cause symptomatic esophageal obstruction. Atypical GERD symptoms are cough, asthma, laryngitis, sore throat, chest pain, abdominal pain, and bloating. These symptoms in the absence of typical GERD symptoms point to diseases other than GERD. Careful investigation of alternative causes of atypical symptoms is necessary. Sophisticated testing, including impedance/ $\mathrm{pH}$ monitoring, must be performed if GERD is believed to be the cause of atypical symptoms and surgery is being considered (Bajbouj et al 2007; Fornari et al 2007). Comparing international literature with our case studies we can confirm that number of patients with atypical symptoms referring to our Referral Center for the Surgical Treatment of Gastroesophageal Reflux Diseases is growing. In fact 644 patients (30.7\%), who underwent to endoscopic exams, showed typical and atypical symptoms (heartburn, pyrosis, regurgitation, asthma, laryngospasm, pulmonary fibrosis), and 96 patients (4.6\%) had only atypical symptoms. 
Reflux esophagitis is defined as reflux causing inflammation or ulceration of the esophagus. Attempts have been made to classify the extent of damage, of which the Los Angeles classification is now the most commonly used:

Grade Extent of esophageal inflammation

A

Mucosal breaks $<5 \mathrm{~mm}$ not extending between folds

B

Mucosal breaks $>5 \mathrm{~mm}$ not extending between folds

C Mucosal breaks extending between folds

D Mucosal breaks extending between $>2$ folds

involving $>75 \%$ of the circumference

\section{Diagnosis}

The signs and symptoms are insufficient to establish a conclusive diagnosis of GERD, regardless of their frequency and intensity, resulting in a diagnostic certainty of around $40 \%$. Endoscopy is not usually performed in young adults patients with typical history of GERD since it does not alter the clinical evolution when compared to the empiric treatment. In patients with non-erosive GERD, the use of the symptom score (moderate or severe) allows a diagnostic certainty of up to $40 \%$ of the cases. In these cases, the upper digestive endoscopy (UDE) does not alter the clinical evolution, when compared to the empiric treatment. It is interesting to remember that, in cases of erosive GERD with typical symptoms, however, the UDE improves the diagnostic accuracy and also establishes a differential diagnosis with other diseases, such as cancer. The 24-hour $\mathrm{pH}$-metry is the most important resource for a definite diagnosis of acid reflux, which constitutes most of reflux episodes, establishing or ruling out the diagnosis with a $90 \%$ and $95 \%$ certainty, respectively. Actually the acid component of the gastric refluxate is responsible for most of the symptoms and pathology associated with GERD, however, other components, such as bile, may also contribute (known as nonacidreflux). Quantification of reflux can be achieved either by measuring acid exposure to the distal esophagus ( $\mathrm{pH}$ studies) or movement of liquid in the distal esophagus (impedance studies). Combined impedance and $\mathrm{pH}$ measurement characterizes all acid and non-acid reflux episodes.

Nearly $70 \%$ of patients with heartburn do not have evidence of erosive changes on endoscopy. Of these, a proportion have increased acid reflux on 24-hour $\mathrm{pH}$ monitoring and are classified as having non-erosive reflux disease (NERD) (Jones et al 1995).

In patients with atypical manifestations, the conventional esophageal $\mathrm{pH}$-metry contributes little to the diagnosis of GERD. The current available evidence does not support the routine use of proximal $\mathrm{pH}$ monitoring. In patients with atypical manifestations, the impedance-pHmetry substantially contributes to the diagnosis of GERD. In patients undergoing prolonged treatment with PPI, the histological esophageal alterations can remain practically unaltered, regardless of the occurrence or not of symptoms and signs. On the other hand, the histological alterations accompany the degree of severity of the esophagitis. Therefore, the evaluation of the histological signs increases the diagnostic probability of GERD. The observation of the dimensions of the distal esophagus intercellular space increases the probability of diagnostic certainty and also allows the analysis of the therapeutic response. Esophageal biopsies in patients with suspected GERD for the analysis of basal cell proliferation allow, in absence of the latter, ruling out the diagnosis or active disease. The isolated presence of the basal layer proliferation, however, has little diagnostic value. Although the basal cell thickness allows the analysis of the therapeutic response, it is not 
correlated with the clinical response. The presence of reflux symptoms in asthmatic patients results in a small increase in the probability of diagnostic certainty. In asthmatic patients with reflux symptoms, the normal $\mathrm{pH}$-metry can predict the absence of therapeutic response with PPI. A significant number of patients with asthma (57\%) also present gastroesophageal reflux.GERD may also produce esophageal injury. Esophagogastroduodenoscopy (EGD) with biopsy has replaced the upright air-contrast phase of the barium esophagram for mucosa evaluation. EGD and biopsy both diagnose and assess esophageal injury by visual and histopathologic mucosal examination. Visual assessment of esophageal injury is graded using the Los Angeles classification. Histopathologic findings, although nonspecific, are confirmatory in the clinical setting of GERD. The finding of specialized columnar epithelium (Barrett esophagus) in the tubular esophagus is secondary to GERD. In the absence of dysplasia, surveillance esophagoscopy and biopsy are required in patients who have Barrett esophagus, regardless of therapy (medical or surgical).

If dysphagia is the predominant symptom and the diagnosis is in question, the examination should start as a timed barium esophagram.

Esophageal manometry excludes unsuspected motility disorders or motility disorders masquerading as GERD, confirms adequate esophageal peristalsis for GERD surgery, and quantifies preoperative resting pressure and relaxation of the lower esophageal sphincter for later comparison. It must be considered in all surgical patients when clinically or phmetrically a motility disorder is suspected.

\section{Management}

The aim of GERD treatment is to effectively control symptoms and prevent GERDassociated complications. As with many conditions, adopting a stepped approach to treatment helps tailor disease severity to treatment regimen.

\subsection{Lifestyle changes}

Simple manoeuvres may have a marked effect on symptoms. These are outlined below:

- dietary changes. Some substances influence oesophageal physiology favouring increased acid reflux. These include fat, caffeine and alcohol

- avoiding late meals. Acid reflux episodes are prolonged when asleep as a result of both gravity, and also reduced peristalsis and acid clearance. Nocturnal reflux can therefore be minimised by consuming small meals long before sleep

- although the association of obesity and GERD is unclear, there does appear to be an association with esophageal adenocarcinoma and many other well-known diseases.11 On this basis weight loss is suggested as part of GERD management.

\subsection{Antacids/alginate combinations}

Antacids consist of calcium carbonate, magnesium and aluminum salts in various compounds or combinations. The effect of antacids is due to partial neutralization of gastric hydrochloric acid and inhibition of the proteolytic enzyme, pepsin. Alginate mechanism of action is due to the formation of a gel in the presence of gastric acid. Alginate-based reforming formulations usually contain sodium or potassium bicarbonate; in the presence of gastric acid, the bicarbonate is converted to carbon dioxide, which becomes entrapped within the gel precipitate, converting it into a foam which floats on the surface of the gastric 
contents, much like a raft on water. Both in vitro and in vivo studies have demonstrated that alginate-based rafts can entrap carbon dioxide, as well as antacid components contained in some formulations, thus providing a relatively $\mathrm{pH}$ neutral barrier. Antacids and alginates have been shown to improve reflux symptoms, however, they do not heal oesophagitis (Stanciu et 1974). They are indicated for very mild symptoms, where step-up treatment is not necessary. There is no role for antacids/alginates in the maintenance of GERD.

Despite the development of potent medications for the treatment of GERD, antacids remain a mainstay of treatment. Antacids neutralize the acid in the stomach so that there is no acid to reflux. The problem with antacids is that their action is brief. They are emptied from the empty stomach quickly, in less than an hour, and the acid then re-accumulates. The best way to take antacids, therefore, is approximately one hour after meals or just before the symptoms of reflux begin after a meal. Since the food from meals slows the emptying from the stomach, an antacid taken after a meal stays in the stomach longer and is effective longer. For the same reason, a second dose of antacids approximately two hours after a meal takes advantage of the continuing post-meal slower emptying of the stomach and replenishes the acid-neutralizing capacity within the stomach.

Antacids may be aluminum, magnesium, or calcium based. Calcium-based antacids (usually calcium carbonate), unlike other antacids, stimulate the release of gastrin from the stomach and duodenum. Gastrin is the hormone that is primarily responsible for the stimulation of acid secretion by the stomach. Therefore, the secretion of acid rebounds after the direct acidneutralizing effect of the calcium carbonate is exhausted. The rebound is due to the release of gastrin, which results in an overproduction of acid. Theoretically at least, this increased acid is not good for GERD.

Acid rebound, however, has not been shown to be clinically important. That is, treatment with calcium carbonate has not been shown to be less effective or safe than treatment with antacids not containing calcium carbonate. Nevertheless, the phenomenon of acid rebound is theoretically harmful. In practice, therefore, calcium-containing antacids such as Tums and Rolaids are not recommended. The occasional use of these calcium carbonatecontaining antacids, however, is not believed to be harmful. The advantages of calcium carbonate-containing antacids are their low cost, the calcium they add to the diet, and their convenience as compared to liquids.

Aluminum-containing antacids have a tendency to cause constipation, while magnesiumcontaining antacids tend to cause diarrhea. If diarrhea or constipation becomes a problem, it may be necessary to switch antacids or alternately use antacids containing aluminum and magnesium.

\subsection{Histamine antagonists}

Although antacids can neutralize acid, they do so for only a short period of time. For substantial neutralization of acid throughout the day, antacids would need to be given frequently, at least every hour. The first medication developed for more effective and convenient treatment of acid-related diseases, including GERD, was a histamine antagonist, specifically cimetidine. $\mathrm{H} 2$ antagonists are very good for relieving the symptoms of GERD, particularly heartburn. However, they are not very good for healing the inflammation (esophagitis) that may accompany GERD. In fact, they are used primarily for the treatment of heartburn in GERD that is not associated with inflammation or complications, such as erosions or ulcers, strictures, or Barrett's esophagus. Four 
different $\mathrm{H} 2$ antagonists are available by prescription, including cimetidine, ranitidine, nizatidine, and famotidine. All four are also available over-the-counter (OTC), without the need for a prescription. However, the OTC dosages are lower than those available by prescription. Histamine is an important chemical because it stimulates acid production by the stomach. Released within the wall of the stomach, histamine attaches to receptors (binders) on the stomach's acid-producing cells and stimulates the cells to produce acid. Histamine antagonists work by blocking the receptor for histamine and thereby preventing histamine from stimulating the acid-producing cells. (Histamine antagonists are referred to as $\mathrm{H} 2$ antagonists because the specific receptor they block is the histamine type 2 receptor.) Because histamine is particularly important for the stimulation of acid after meals, $\mathrm{H} 2$ antagonists are best taken 30 minutes before meals. The reason for this timing is so that the $\mathrm{H} 2$ antagonists will be at peak levels in the body after the meal when the stomach is actively producing acid. $\mathrm{H} 2$ antagonists also can be taken at bedtime to suppress nighttime production of acid.

\subsection{Proton pump inhibitors}

The second type of drug developed specifically for acid-related diseases, such as GERD, was a proton pump inhibitor (PPI), specifically, omeprazole. A PPI blocks the secretion of acid into the stomach by the acid-secreting cells. Proton pump inhibitors (PPIs) bind to enzymes in the stomach membrane that produce hydrochloric acid. PPIs reduce levels of stomach acid, and are commonly used to reduce acid reflux symptoms, heal ulcers, and treat gastroesophageal reflux disease (GERD).The advantage of a PPI over an $\mathrm{H} 2$ antagonist is that the PPI shuts off acid production more completely and for a longer period of time. Not only is the PPI good for treating the symptom of heartburn, but it also is good for protecting the esophagus from acid so that esophageal inflammation can heal. PPIs are used when $\mathrm{H} 2$ antagonists do not relieve symptoms adequately or when complications of GERD such as erosions or ulcers, strictures, or Barrett's esophagus exist. Five different PPIs are approved for the treatment of GERD, including omeprazole, lansoprazole, rabeprazole, pantoprazole, and esomeprazole. A fifth PPI product consists of a combination of omeprazole and sodium bicarbonate. PPIs are best taken an hour before meals. The reason for this timing is that the PPIs work best when the stomach is most actively producing acid, which occurs after meals. If the PPI is taken before the meal, it is at peak levels in the body after the meal when the acid is being made. Esomeprazole $20 / 40 \mathrm{mg} /$ day, lansoprazole $30 \mathrm{mg} /$ day, omeprazole $20 / 40 \mathrm{mg} /$ day, pantoprazole $40 \mathrm{mg}$ / day and rabeprazole $20 \mathrm{mg}$ /day are equivalent in the treatment of patients with erosive and non-erosive GERD. The report of the occurrence of neoplasia with the chronic use of PPI is not supported by evidence. The gastric mucosa, however, is altered in these conditions (chronic gastritis, atrophy and polyps of fundic glands). The prevalence of gastric atrophy signs increases along the years, mainly when $H$. pylori is present.

At the primary care level, PPI or a combination of alginate-antacid and acid suppressive therapy can be administered at the discretion of the physician, as combination therapy, which may potentially be more beneficial than acid suppressive therapy alone. Similarly, patients who fail full-dose PPIs, plus/minus adjuvant therapies, may benefit from step-up therapy to twice daily PPIs even if there is no difference in randomized studies regarding the clinical response to the treatment with PPI taken as two daily doses, when compared to a single daily dose. 
When the PPI were used in full dose (esomeprazole: $20 \mathrm{mg} /$ day and $40 \mathrm{mg} /$ day; lansoprazole: $15 \mathrm{mg} /$ day and $30 \mathrm{mg} /$ day; omeprazole: $40 \mathrm{mg} /$ day; pantoprazole 20 $\mathrm{mg}$ /day and $40 \mathrm{mg} /$ day; rabeprazole: $10 \mathrm{mg} /$ day and $20 \mathrm{mg} /$ day), no statistical difference was observed between 4 and 8 weeks of treatment. Nevertheless, in cases of therapeutic failure, the time of treatment can be extended from 4 to 8 weeks, as although no significant difference was observed between the two periods, the number of satisfactory responses is higher after 8 than after 4 weeks.

\subsection{Pro-motility drugs}

Pro-motility drugs work by stimulating the muscles of the gastrointestinal tract, including the esophagus, stomach, small intestine, and/or colon. One pro-motility drug, metoclopramide, is approved for GERD. Pro-motility drugs increase the pressure in the lower esophageal sphincter and strengthen the contractions (peristalsis) of the esophagus. Both effects would be expected to reduce reflux of acid. However, these effects on the sphincter and esophagus are small. Therefore, it is believed that the primary effect of metoclopramide may be to speed up emptying of the stomach, which also would be expected to reduce reflux. Pro-motility drugs are most effective when taken 30 minutes before meals and again at bedtime. They are not very effective for treating either the symptoms or complications of GERD. Therefore, the pro-motility agents are reserved either for patients who do not respond to other treatments or are added to enhance other treatments for GERD.

\subsection{Foam barriers}

Foam barriers provide a unique form of treatment for GERD. Foam barriers are tablets that are composed of an antacid and a foaming agent. As the tablet disintegrates and reaches the stomach, it turns into foam that floats on the top of the liquid contents of the stomach. The foam forms a physical barrier to the reflux of liquid. At the same time, the antacid bound to the foam neutralizes acid that comes in contact with the foam. The tablets are best taken after meals (when the stomach is distended) and when lying down, both times when reflux is more likely to occur. Foam barriers are not often used as the first or only treatment for GERD. Rather, they are added to other drugs for GERD when the other drugs are not adequately effective in relieving symptoms. There is only one foam barrier, which is a combination of aluminum hydroxide gel, magnesium trisilicate, and alginate.

\section{Surgery}

When the diagnosis of reflux is objectively confirmed, surgical therapy should be considered in individuals who (Rice et al 2008):

1. have failed medical management (inadequate symptom control, severe regurgitation not controlled with acidsuppression, or medication side effects)

OR

2. opt for surgery despite successful medical management (due to quality of life considerations, lifelong need for medication intake, expense of medications, etc.)

OR

3. have complications of GERD (e.g., Barrett's esophagus, peptic stricture) (Spechler et 1996; Lagergren et al 1999) 
OR

4. have extra-esophageal manifestations (asthma, hoarseness, cough, chest pain, aspiration) (Rakita et al 2006; Oelshlager et al 2002).

The coexistence of Barrett's esophagus with gastroesophageal reflux symptoms is considered by many a clear indication for antireflux surgery (Oelshlager et al 2002). Surgical intervention for asymptomatic Barrett's esophagus is more controversial, however. While the metaplastic changes of Barrett's have been reported to regress to a greater degree in the post-surgical population compared with medically treated patients, to date there is no demonstrable improvement in esophageal adenocarcinoma rates (Rossi et al 2006; Chang et al 2007).

Today there is increased tendency worldwide to utilize surgery in the earlier stages of the disease (Spechler et al 2001). This change in clinical practice is mainly due to advancements in surgical technique, the increased patient satisfaction by laparoscopy, and the increased awareness of the impairment in quality of life of patients who are not efficiently treated. Moreover, the increasing enthusiasm of patients and surgeons for minimally invasive surgery has led to the wider application of laparoscopy in the management of GERD in many institutes worldwide.

The large success of laparoscopic surgery as an effective treatment of gastroesophageal reflux disease, has established minimal invasive surgery as the gold standard in the surgical treatment of this condition.

The guidelines from American Society for Gastrointestinal and Endoscopic Surgeons (SAGES) claim that surgery in GERD is curative in $85-93 \%$ of cases and suggest that the procedure may be appropriate in patients who have failed medical management, decide for surgery despite successful medical management, have complication of GERD, have medical complications attributable to a large hiatal hernia, or have "atypical" symptoms and reflux documented on $24 \mathrm{~h} \mathrm{pH}$ monitoring (SAGES Guidelines 2010).

Antireflux surgery has been shown to be very effective in relieving symptoms in $88-95 \%$ of patients, with excellent patients satisfaction, both in short and long term studies (Laffularde et al 2001; McKenzie et al 1996).

There are several trials favoring the clinical outcome of laparoscopic antireflux surgery compared to long-term PPI therapy. A large randomized clinical trial from the UK has shown significantly better physiological control of reflux in patients having undergone laparoscopic Nissen fundoplication than patients under maintenance PPI therapy (Laffularde et al 2001).

A randomized trial with 5-year follow-up, demonstrated that antireflux surgery is more effective than proton pomp inhibitor (PPI) drugs in controlling GERD symptoms (Laffularde et al 2001; Lundell et al 2001).

At 7-years follow-up Lundell et all reported the results of a randomized controlled trial of patients with esophagitis treated with omeprazole or surgery. The two treatments were similar regarding the incidence of recurrent esophagitis (10.3\% omeprazole versus $11.8 \%$ antireflux surgery). In addition the two therapies appeared to be equivalent in healing esophageal mucosa (Lundell et al 2007).

Another randomized trial, with 10 year follow-up, evaluating the effectiveness of medical therapy (omeprazole) versus antireflux surgery found that patients who underwent surgery had improved symptoms' relief when compared to the medically treated group (Spechler et al 2001). 
After 1991 when Dallemagne et al (Dallemagne et al 1991)performed the first laparoscopic Nissen Fundoplication, this technique was preferred to open procedures to result in lower morbidity and mortality, shorter hospital stay, faster recovery and less postoperative pain. In a review by Catarci et al, laparoscopic fundoplication was as effective as its open counterpart with reduced morbidity, shorter hospital stay, and recovery but without any significant difference in early functional results and outcome (Catarci et al 2004).

Salminen et al in a recent randomized controlled trial, with 11-year follow-up, compared laparoscopic approach and conventional Nissen Fundoplication and concluded that the open and laparoscopic approaches for the Nissen fundoplication have similar long-term subjective symptomatic outcome despite the significantly higher evidence of incisional hernia and defective fundic wraps at endoscopy in the open group (Salminen et al 2007).

In a recent review Peters and colleagues compared 503 laparoscopic anti-reflux surgery and 533 open anti-reflux surgery. In this meta-analysis the authors conclude that laparoscopic anti-reflux surgery enables a faster convalescence and return to productive activity, with a reduced risk of complications and a similar treatment outcome compared with that of the open approach (Peters et al 2009).

The surgical management of GERD has been difficult to study scientifically because of the significant variation in the surgical techniques used.

The LOTUS trial (Attwood et al 2008)was designed to identify a methodology for standardization of the surgical technique and to measure the effectiveness of this standardization. This study has shown that surgeons are able to standardize their work for the purpose of measuring the outcome of an operative procedure within the context of a randomized trial.

Several series have shown the early outcomes of laparoscopic Nissen fundoplication to be excellent, with minimal morbidity and mortality, marked reduction in distal esophageal acid exposure, and symptom control for the overwhelming majority of patients. There have been multiple series with 5-year outcomes following Laparoscopic Nissen Fundoplication (Table 1). Heartburn was controlled in approximately $90 \%$ of patients, the revision rate was between 1 and $17 \%$, and $86 \%-92 \%$ of patients that were off antireflux medications.

In the German experience, in 164 hospitals performing laparoscopic antireflux surgery and 2053 operation were reported in 1999. In 65\% of the cases the surgical procedures were total fundoplication, in $31 \%$ partial fundoplication and in $4 \%$ other techniques. In total fundoplication there were 5 different techniques, in partial plication 5 and in the other group 3 (Huttl et al 2005).

Actually in laparoscopic antireflux surgery there are two debated questions today: if partial or total fundusplication must be performed and if this last is preferred division of short gastric vessels must be routinely performed or not.

\subsection{Partial versus total fundoplcation}

The total fundoplication involves a 360-degree wrap of the gastric fundus around the esophagus and is the most commonly performed anti-reflux operation. Total wrap (Nissen) supports and acknowledge the fact that the wrap needs to be "floppy" to minimize postoperative dysphagia (DeMeester et al 1986). It should also be noted that a floppy Nissen fundoplication is safe and effective in patients suffering from a defective esophageal peristalsis. Finally, proponents of the Nissen note a decreased effectiveness of a partial Fundoplication in controlling reflux symptoms. 


\begin{tabular}{|l|c|c|c|c|c|}
\hline Series & FU (years) & N (\%FU) & $\%$ Hb Relief (0-1) & Revision (\%) & $\begin{array}{c}\text { Off PPI+H2-A } \\
(\%)\end{array}$ \\
\hline $\begin{array}{l}\text { Morgenthal et al. 2007 } \\
\text { Emory, GA, USA) }\end{array}$ & 11,0 & $166(59)$ & 89 & 10,8 & 70 \\
\hline $\begin{array}{l}\text { Dallemagne et al. 2006 } \\
\text { (Belgium) }\end{array}$ & 10,3 & $45(66)$ & 96 & 1,4 & $92^{*}$ \\
\hline $\begin{array}{l}\text { Kelly et al. 2007 } \\
\text { (Australia) }\end{array}$ & 10 & $226(90)$ & 84 & 17 & 79 \\
\hline $\begin{array}{l}\text { Zaninotto et al. 2007 } \\
\text { (Italy) }\end{array}$ & 8,1 & $138(95)$ & - & 9,4 & 79 \\
\hline $\begin{array}{l}\text { Bammer et al. 2001 (mayo, } \\
\text { FL, USA) }\end{array}$ & 6,4 & $171(59)$ & 94 & 1,0 & $86^{*}$ \\
\hline $\begin{array}{l}\text { Laffularde et al. 2001 } \\
\text { (Australia) }\end{array}$ & 6 & $166(93)$ & 87 & 14,2 & 89 \\
\hline $\begin{array}{l}\text { Oelschlager et al 2008 } \\
\text { (Seattle, WA, USA) }\end{array}$ & 5,8 & $288(65)$ & - & 3 & 88 \\
\hline $\begin{array}{l}\text { Anvari, Allen 2003 } \\
\text { (Ontario, Canada) }\end{array}$ & 5 & $181(48)$ & - & 3,6 & 86 \\
\hline $\begin{array}{l}\text { Booth et al. 2002 } \\
\text { (England) }\end{array}$ & 4 & $140(78)$ & 90 & 6,3 & \\
\hline
\end{tabular}

$\mathrm{FU}=$ follow-up; $\mathrm{HB}=$ heartburn; 0-1= none-mild; *Does not include patients on H2-A

Table 1. Laparoscopic $360^{\circ}$ Fundoplication Series

Two partial fundoplications are commonly performed, the Dor and Toupet fundoplication (anterior and posterior wrap). Of these two partial wraps, the Toupet is the most commonly performed partial Fundoplication (Roberts et al 2006).

The Nissen procedure finds excellent symptomatic control but is reported to also have a high postoperative dysphagia rate and specific side effects such as inability to belch and vomit, and gas bloat syndrome (Sgromo et al 2008; Watson et al 2001).

The Toupet procedure is thought to produce less postoperative side effects than the Nissen procedure but studies have indicated that the recurrence rate of reflux symptoms may be higher after this procedure (Yobe et al 1997; Fernando et al 2002).

Horvath et al defines in a study the preoperative risk factors that predispose patients to failure. Data from 48 patients with objective follow-up performed as a part of a prospective long-term outcome project: 24-h pH-monitoring, manometry, esophagogastroduodenoscopy at 6 months, 3 years and 6 years, was analyzed (Horvath et al 1999). Patients in whom testing was completed were divided into two groups based on their results: those whose procedures failed $(n=22)$ and those who had a successful outcome after a Toupet fundoplication $(n=26)$. Surgical failure was defined as an abnormal postoperative De Meester score, with or without symptomatic recurrence. The authors shows that age, sex, primary and secondary presenting symptoms, presence of hiatal hernia, and esophageal dysmotility were not predictive of failure following a Toupet procedure and the numbers of years of GERD symptoms before surgery also did not predict failure after Toupet fundoplication. Horvath and colleagues concluded that the laparoscopic Toupet fundoplication appears to provide a weaker antireflux barrier than the Nissen procedure and is probably an insufficient procedure for patients with severe GERD. It may also 
predispose patients to postoperative mediastinal warp hernation. Independent preoperative predictors of failure after Toupet were:

- $\quad$ LES pressure $<5 \mathrm{mmHg}$ an preoperative manometry,

- Distal esophageal aperistaltic segment,

- Biopsy proved Barrett's metaplasia,

- Presence of stricture,

- Grade III or IV esophagitis an endoscopy,

- $\quad$ Preoperative De Meester score $>50$.

Guerin et al in a recent randomized trial with a 3 years follow-up, compared Nissen versus Toupet Fundoplication. Both groups in this study presented comparable preoperative findings (Guerin et al 2007). The Toupet procedure presented a higher level of invaliding functional symptoms in the immediate postoperative period, and the difference with the Nissen Fundoplication group was statistically significant for hyperflautolence, solids dysphagia and incapacity to belch. But at 1 and 3 years follow-up there wasn't any statistically significant difference of invalidating symptoms and the satisfaction level remained high. The authors concluded that the choice of the technique did not seem to be determined by the preoperative investigations, except when it diagnosticated a brachy esophagus and they also confirmed that laparoscopic Nissen or Toupet Fundoplication provides a high level of patients satisfaction despite invalidating side effects during the first postoperative year.

Strate et al compared laparoscopic Toupet and Nissen Fundoplication in 200 patients with esophageal motility disorders within 2 years follow-up (Strate et al 2008). The authors led to the following conclusion:

- Esophageal motility disorder does not effect postoperative clinical outcome and requires no tailoring of surgical management;

- $\quad$ The Toupet procedure is more effective in reflux control;

- Postoperative dysphagia is significantly higher after Nissen Fundoplication;

- Toupet Fundoplication reduces the rate of reoperation due to mechanical failure.

For Strate and colleagues the Toupet Fundoplication seems to be the better operative procedure for patients suffering from GERD.

Another similar randomized clinical trial by Booth and colleagues compared the two procedures in 127 patients considering preoperative esophageal manometry after 1 year follow-up (Booth et al 2008). In the study there was no significant difference in the prevalence or severity of symptoms after surgery between the Nissen group and Toupet group except for a greater prevalence of dysphagia and chest pain when eating in the Nissen group and there were no postoperative differences in the prevalence or severity of symptoms between the effective and ineffective motility groups, other than an increased severity score for flatus in the effective motility group 6 months after surgery. At 1 year follow-up there were no significant differences in Visick score between Nissen and Toupet group. The authors provides no clear conclusions regarding the efficacy and durability of Nissen compared with Toupet Fundoplication in controlling the reflux symptoms of heartburn and regurgitation, although there are greater postoperative acid exposure time and more $\mathrm{pH}$ failures in the Toupet group.

Sgromo et al compared the long-term outcome of Nissen and Toupet fundoplication by evaluating symptoms and quality of life at 7 years follow-up (Sgromo et al 2008). The authors concluded that long-term satisfaction, general symptoms score and quality of life 
were equivalent after laparoscopic Nissen or Toupet fundoplication, despite, a significantly increased prevalence of persistent heartburn after laparoscopic Toupet fundoplication.

Kamolz et al used the Gastrointestinal Quality of Life Index (GIQLI) for evaluating Nissen laparoscopic fundoplication versus Toupet procedure (Kamolz et al 2002). At 3 years and 5 years follow-up, the analysis of quality of life data showed that the GIQLI score remained stable in comparison with the 1 year follow-up data. Patients satisfaction with surgery was rated as "excellent" or "good" in $97.7 \%$ of patients. There were no significant differences between the 2 groups. The authors concluded that quality of life scores for both surgical groups were almost equal and postoperative outcome were comparable to values in healthy controls.

In a similar retrospective study, Zugel et al compared the results of 122 Toupet and 40 Nissen laparoscopic fundoplication in terms of patients satisfaction at 19 months follow-up. Both groups offered effective therapy for reflux, with more than $90 \%$ patient satisfaction (Zugel et al 2002). The authors concluded that both surgical techniques were effective in the treatment of GERD.

Laws et al used a randomized prospective study to compare the Nissen fundoplication versus the Toupet fundoplication for GERD (Laws et al 1997). At 27.2 months follow-up, postoperative symptomatology was judged using a modified Visick scale using the following grades in 38 patients:

- I no symptoms,

- II minimal symptoms, no lifestyle changes, no need to see a doctor,

- $\quad$ III significant symptoms requiring lifestyle changes of doctor's help,

- IV debilitating symptoms or reoperation.

There were no grade IV's. At follow-up, Visick score after the Nissen wrap were I-13, II-8, III-2 and after the Toupet procedure were I-12 and II-3. The authors concluded that a partial or complete wrap after division of the short gastric vessels offers effective therapy for reflux esophagitis with $>90 \%$ patients satisfaction.

Farrell and colleagues compared the effectiveness and durability of Toupet (79 pts) and Nissen (59 pts) procedures as a function of preoperative esophageal motility (Farrell et al 2000). Patients scored heartburn, regurgitation and dysphagia preoperatively, and at 6 weeks and 1 years, using 0 to 3 scale. At 6 weeks after operation, heartburn and regurgitation were similarly improved in both groups, but dysphagia was more prevalent among Nissen patients. After 1 year, heartburn and regurgitation were re-emerging in Toupet patients, and dysphagia was again similar between groups. Patients with impaired motility who have Nissen fundoplication are no more likely to suffer persistent dysphagia than their counterparts who have Toupet fundoplication. But, patients with normal motility are more likely to develop symptoms recurrence after Toupet fundoplication than Nissen procedure, with no distinction in dysphagia rates. The authors concluded that Toupet patients suffer more heartburn recurrence than Nissen patients, with similar dysphagia.

Fernando et al compared Toupet procedure versus Nissen fundoplication (Fernando et al 2002). Extended outcome and quality of life measurement (SF36 and HRQOL) were available for 142 patients at a mean follow-up of 19.7 months. Since there was a potential bias with a greater proportion of esophageal dysmotility with Toupet patients, further analysis was performed by dividing patients into four groups: group 1, Nissen patients with decreased motility; group 2, Toupet patients with decreased motility; group 3, Nissen patients with normal motility; and group 4, Toupet patients with normal motility. 
Comparison were made as follows: group 1 versus group 2, group 3 versus group 4, and group decreased motility versus group normal motility. There were no significant differences between Nissen and Toupet groups except for a higher incidence of dysphagia in the Toupet group. Resumption of proton pump inhibitors was required in $20 \%$ Nissen patients compared to $38 \%$ Toupet patients $(\mathrm{p}<0.05)$. Only $7 \%$ in the Nissen group were dissatisfied with their surgery compared to $21 \%$ patients in the Toupet group $(p<0.05)$. The SF36 scores were similar in all quality of life domains except for the domain of physical function, where better scores were seen in the Nissen group compared to the Toupet group $(\mathrm{p}<0.05)$. Comparison of group 1 versus group 2 revealed no significant difference in SF36 and HRQOL scores, symptoms, and medication use. Comparison of group 3 versus 4 demonstrated slightly worse HRQOL scores in the Toupet group and poorer scores $(\mathrm{p}<0.05)$ in the SF36 domains of vitality and mental health for the Toupet patients. The Toupet patients with normal motility also complained of more dysphagia and waterbrash $(\mathrm{p}<0.05)$. Comparison was also made between patients with impaired motility and those with normal motility. There were no differences in SF36 scores, HRQOL score, symptoms and medication use. This analysis supports the hypothesis that the differences seen were related to differences in esophageal motility. Surprisingly, they found more dysphagia in the Toupet group. These differences was not seen when they were analyzing the results of patients in the impaired motility groups but was present in patients with normal motility. The reason for this is unclear but may be related to a greater degree of recurrent esophagitis because of reflux in Toupet patients.

Dallemagne and colleagues compared laparoscopic Nissen fundoplication versus Toupet procedure at 5 years and 10 years follow-up (Dallemagne et al 2006). At 5 years follow-up, 58 Nissen patients and 28 Toupet patients completed the study, and at 10 years 49 Nissen and 20 Toupet patients completed the follow-up. At 5 years the heartburn was relieved in $98 \%$ of the Nissen group and $86 \%$ of the Toupet group. There was no significant difference between the two groups. Ten years after surgery the heartburn still was controlled in $96 \%$ of Nissen patients and $90 \%$ of Toupet group. Also in this case there was no significant difference between the two groups. Kaplan-Meier estimates of recurrence-free proportion were evaluated and control of reflux was still obtained in $93.3 \%$ of the Nissen groups and $81.8 \%$ of Toupet patients at 10 years $(p=0.17)$. There was no significant difference in the incidence of side effects between partial and total fundoplication. The incidence of postoperative dysphagia in patients with preoperative impaired esophageal motility was not different after partial or total fundoplication. Dallemagne and colleagues concluded that Nissen patients have better results than Toupet patients, although the differences was not statistically significant and they observed more recurrences after partial fundoplication than after Nissen fundoplication.

Fein et al compared partial fundoplication versus total fundoplication at 10 years follow-up. 88 patients received a Nissen procedure and 10 a Toupet fundoplication (Fein et al 2008). Follow-up of the patients included disease-related questionnaire and GastroIntestinal Quality of Life Index (GIQLI). Positive pH score were $21 \%$ in Nissen group and $56 \%$ in Toupet patients. The heartburn was present in $29.7 \%$ of Nissen groups and $12.5 \%$ of Toupet patients, regurgitation in $15.1 \%$ of the Nissen group and $10 \%$ of the Toupet group, dysphagia in $30.6 \%$ of the Nissen group and $28.6 \%$ of the Toupet group. Patients who had undergone Toupet fundoplication (43\%) took proton pump inhibitors significantly more often than patients who underwent Nissen fundoplication (14\%). None of the differences 
regarding the various procedures were significant about the GIQLI. In the observational scores, Nissen fundoplication appeared to control reflux better than partial fundoplication. In conclusion, despite the difficulties in comparing the result of single experiences of partial and total placation almost all combined experiences reported a good clinical and instrumental result for Toupet and Nissen procedures with light preference of Nissen for a better reflux control with similar others side effects.

\subsection{Division versus non division of the short gastric vessels}

The total fundoplication wrap achieves very effective control of reflux, although it can be followed by some troublesome side effects, such as dysphagia, gas bloat and inability to belch. To minimize the risk of developing these side effects, Nissen's procedure has been modified in a variety of ways concerning the length of the placation (short: $2 \mathrm{~cm}$, long: 3-4 $\mathrm{cm}$ ), its contention's degree (tight or floppy), the fixation of posterior wrap to the diaphragm or the esophagus, the routine iatal repair and the routine division of the first two or three short gastric vessels (true, Nissen) or it's preservation (Rossetti variation). There is a general agreement in literature to prefer a short floppy placation with no routine iatal repair and no wrao fixation. A still debated question is the significance of short gastric vessels division (deMeester et al 1986). It has been claimed that this step is followed by a lower risk of dysphagia, gas bloat and other side effects (deMeester et al 1986; Donehaue et al 1985) However, some surgeons claim that an equally good outcome can be achieved without dividing these vessels (Rossetti et al 1977; Watson et al 1997; Watson et al 1995; Anvari et al 1996) and this evidence is confirmed by randomized controlled trial.

Chryos et al in a prospective randomized trial compared Nissen (with division gastric vessels) to Nissen-Rossetti (without division gastric vessels) technique after 12 months follow-up (Chryos et al 2001). The authors concluded that division of short gastric vessels while performing laparoscopic Nissen fundoplication does not improve clinical outcome and laboratory finding in patients with GERD, and, at the same time, is associated with prolongation of the operating time and increased incidence of postoperative gas bloat syndrome.

In a recent multicentric trial of 1340 patients, Pessaux et al, concluded that the division of short gastric vessels did not improve clinical outcome after 2 or 5 years follow-up and increased the incidence of gas discomfort (Pessaux et al 2005).

In a recent randomized controlled trial Yang, Watson and colleagues reported the clinical outcome at 10 years follow-up (Yang et al 2008). The surgeons of this study have just reported the 6 months and 5 years outcome from this trial in previous publications (O'Boyle et al 2002; Watson et al 1997).

The authors confirm what many other papers claim: the division of the short gastric vessels does not influence the clinical outcome (Luostarinen et al 1999; Blomqvist et al 2000).

At 10 years follow-up, the authors concluded that there were no significant differences between the 88 patients that completed the study for either incidence or severity of dysphagia, heartburn, or overall satisfaction. These outcomes were identical to the outcomes from the earlier follow-up.

In a study of 138 patients, Sato et al analyzed the effect of short gastric vessels division on postoperative dysphagia (Sato et al 2002). They reported that laparoscopic Nissen fundoplication with or without division of short gastric vessels achieved a similar outcome. Their research suggested that patient selection and accurate construction of the fundoplication were the most important factors in minimizing postoperative dysphagia. 
Mardani, Lundell and colleagues designed a randomized controlled trial to determine the long-term results of total Nissen Fundoplication with or without division of short gastric vessels in a 10 years follow-up (Mardani et al 2009). They reported that mechanical sideeffects remain a problem following construction of a total wrap, and are perhaps of even greater concern when the operation is performed laparoscopically. There is a widely held view among surgeons that a wrap should be short end tension free (deMeester et al 1986; Rossetti et al 1977). However, the optimal length of total wrap to minimize subsequent obstructive complaints remains to be clarified in Mardani and colleagues randomized trial, in fact it may sometimes be necessary to divide some of the short gastric vessels in order to construct a tension free wrap, but this cannot be recommended in routine surgical practice (Mardani et al 2009). In a precedent report the same authors have reported subtle manometric differences between the two study groups, offering a physiologic background to a potential difference in functional outcome (Engstrom et al 2004), but it appears that these differences in lower esophageal sphincter response to gastric distension with air do not translate into important and clinically relevant functional correlates.

At 10 years follow-up, the authors concluded that with total Fundoplication it makes no difference whether the fundus is mobilized or not and that both types of repair provide long-lasting control of reflux (Mardani et al 2009).

Leggett et al. compared laparoscopic Nissen Fundoplication and Rossetti's modification in 239 patients, follow-up for the Rossetti group (138 patients) extends from 36 to 82 months and that for the Nissen group (101 patients) from 17 to 35 months (Leggett et al 2000). All patients experienced relief from symptomatic gastroesophageal reflux, whether they received the Rossetti modification or the Nissen Fundoplication. In their series, they found no statistically significant differences in intraoperative, postoperative, or overall complications between the two procedures. Prolonged postoperative dysphagia requiring dilation was significantly higher in the Rossetti group than in the Nissen group. But the percentage of patients requiring dilatation in both groups was higher in the first 20 than in the last 20 cases, and the authors state that with experience, surgeons become better able to judge the tightness of the crural closure, the size of posterior window, and the looseness of the wrap.

Table 2 shows of results of a different series that compared total fundoplication with or without division short gastric vessels.

In another prospectively randomized trial Kosek and colleagues compared the clinical and functional results after total fundoplication with or without division of short gastric vessels after five years follow-up (Kosek et al 2009). During long-term follow-up median DeMeester score decreased without statistically significant differences between the two groups and Gastrointestinal Quality of Life and patient satisfaction were similar in both group. The authors concluded that in their patient population division of the short gastric vessels during Nissen fundoplication that it has no statistically significant influence on clinical or functional outcome during a 5-year follow-up period. They therefore do not recommend routine division of the short gastric vessels in the course of total fundoplication. The intraoperative decision to divide the vasa gastricae breves may be made in some patients to obtain a tension-free fundoplication.

Finally in spite that many authors still routinely employ Nissen technique to perform a 360 degree short fundoplication there is no evidence support this position according to randomized study.

Rossetti variation (without section of short gastric vessels) can be "short e floppy" as well according the surgeon's experience and the use of an endoesophageal bougie of $54-60 \mathrm{Fr}$. 


\begin{tabular}{|l|c|c|c|c|c|c|c|c|}
\hline & \multicolumn{2}{|c|}{$\begin{array}{c}\text { Crysos et al. - } \\
12 \text { months FU * }\end{array}$} & \multicolumn{2}{c|}{$\begin{array}{c}\text { Pessaux et al. - } \\
5 \text { years FU * }\end{array}$} & \multicolumn{2}{c|}{$\begin{array}{c}\text { Yang et al. - } \\
10 \text { years FU }\end{array}$} & \multicolumn{2}{c|}{$\begin{array}{c}\text { Mardani et al. - } \\
10 \text { years FU ** }\end{array}$} \\
\hline & $\begin{array}{c}\text { Not } \\
\text { Divided } \\
32 \mathrm{pt}\end{array}$ & $\begin{array}{c}\text { Divided } \\
24 \mathrm{pt}\end{array}$ & $\begin{array}{c}\text { Not } \\
\text { Divided } \\
404 \mathrm{pt}\end{array}$ & $\begin{array}{c}\text { Divided } \\
305 \mathrm{pt} \text { divided } \\
44 \mathrm{pt} \\
(\%)\end{array}$ & $\begin{array}{c}\text { Divided } \\
44 \mathrm{pt}(\%)\end{array}$ & $\begin{array}{c}\text { Not Divided } \\
31 \mathrm{pt}\end{array}$ & $\begin{array}{c}\text { Divided } \\
42 \mathrm{pt}\end{array}$ \\
\hline Reccurence & - & - & $35(8,7)$ & $\begin{array}{c}40 \\
(13,1)\end{array}$ & - & - & - & - \\
\hline Heartburn & 0 & $1(4)$ & - & - & 18 & 11 & $1,9(1,4)$ & $1,4(0,7)$ \\
\hline Chest pain & $1(3)$ & 0 & $1(0,25)$ & 0 & - & - & - & - \\
\hline Regurgitation & 0 & 0 & - & - & 17 & 9 & - & - \\
\hline Respiratory & $2(16)$ & $1(4)$ & $2(0,5)$ & $2(0,6)$ & 20 & 24 & - & - \\
\hline Dysphagia & $5(16)$ & $4(17)$ & $26(6,4)$ & $28(9,2)$ & & & $2,4(1,6)$ & $2,0(1,5)$ \\
\hline Solids & 5 & 4 & - & - & 44 & 59 & - & - \\
\hline Liquids & 0 & 0 & - & - & 14 & 14 & - & - \\
\hline $\begin{array}{l}\text { Gas-bloating } \\
\text { Syndrome }\end{array}$ & $6(19)$ & $9(38)$ & $44(10,9$ & $26(8,5)$ & 32 & 41 & - & - \\
\hline Diarrhea & - & - & $3(0,7)$ & $7(2,3)$ & - & - & $2,6(1,6)$ & $2,4(1,5)$ \\
\hline Indigestion & - & - & $3(0,7)$ & $6(2)$ & - & - & $3,1(1,5)$ & $3,4(1,2)$ \\
\hline Constipation & - & - & $1(0,25)$ & 0 & - & - & $2,3(1,2)$ & $2,4(1,3)$ \\
\hline $\begin{array}{l}\text { Abdominal } \\
\text { pain }\end{array}$ & - & - & $4(1)$ & $7(2,3)$ & - & - & $2,8(1,4)$ & $2,5(1,2)$ \\
\hline Hiccup & - & - & $2(0,5)$ & $2(0,6)$ & - & - & - & - \\
\hline Flatulence & - & - & $8(2)$ & $12(4)$ & - & - & - & - \\
\hline Nausea & - & - & 0 & $1(0,3)$ & 10 & 21 & - & - \\
\hline
\end{tabular}

$\mathrm{Pt}=$ patients; ${ }^{*}=$ Numbers in parentheses represent percentages. ${ }^{* *}=$ Values are mean (s.e.m.). In all series no significant differences demonstrated between trial groups.

Table 2. Laparoscopic Total fundoplication: not divided (Nissen-Rossetti procedure) vs divided (Nissen procedure) short gastric vessels

In the few cases in which a "floppy" placation is not feasible than short gastric vessels must be divided and there a Nissen procedure performed.

In conclusion, Laparoscopic fundoplication is an established treatment for symptomatic gastro esophageal reflux disease and must be considered now days as the "gold standard" surgical procedure, tailoring a only marginal role to open surgery. It effectively controls heartburn and regurgitation, but it can be associated with unwanted effects, principally postoperative dysphagia, postprandial fullness, inability to belch or vomit and increased passage of flatus (tab. 2).

The choice of a total (360 degree) or a partial (270 degree) placation is difficult and not supported with clear evidence both in randomized and non randomized series, even if a better control of reflux symptoms in long follow-up studies gave a reason of a much a larger experience of 360 degree plication performed by reflux surgeon.

Total fundoplication is than the most performed operation for surgical treatment of GERD. Division of short gastric vessels (Nissen) or their preservation (Rossetti variation) is the last debated point. Randomized and non-randomized studies seem to point out in a precise way 
that a division of short gastric vessels is unnecessary to perform a "short and floppy" placation: the two main objectives to achieve is to prevent post operative dysphagia.

\section{Barrett's esophagus}

Barrett's esophagus is an acquired abnormality that is characterized grossly by an upward displacement of the squamo-columnar junction, with replacement of the typical whitish smooth esophageal mucosa by a velvety, reddish mucosa (Oelschlager et 2003). The columnar-lined esophagus was described by Norman Barrett in 1950 (Barrett 1950), reported to be associated with gastroesophageal reflux disease in 1953 (Allison et al 1953) and convincingly linked with oesophageal adenocarcinoma in 1975 (Naef et al 1975). The paradigm is that Barrett's esophagus arises as a complication of symptomatic gastroesophageal reflux disease and predisposes to esophageal adenocarcinoma.

BE is detected in approximately $6-12 \%$ of patients with GERD (Winters et al 1987, Cameron et al 1992). At present, BE is the most common cause of esophageal adenocarcinoma, a deadly malignancy with a frequency that has been rising strikingly in Western countries and a mortality rate that still exceeds $80 \%$ (Parker et 1997). In the USA, the incidence of esophageal adenocarcinoma has increased more than sixfold over the past three decades (Pohl et al 2005). The absolute risk of patients with BE for developing cancer is approximately $0.5 \%$ per year (Hirota et al 1999).

The metaplastic mucosa was confirmed by biopsy of the tubular esophagus during endoscopy.

Controversy over criteria for diagnosis of BE primarily concerns whether intestinal metaplasia (IM) is required for a diagnosis of BE. In the USA, BE has been defined by the Parameters Committee of the American College of Gastroenterology as the metaplastic replacement of any length of the esophageal epithelium that can be recognized at endoscopy and that is confirmed by biopsy to have specialized intestinal metaplasia, defined by the presence of goblet cells (Wang et al 2008). The vast majority of adenocarcinomas of the esophagus are accompanied by IM in multiple studies (Paraf et al 1995; Cameron et al 1995, Smith et al 1984). Therefore, it has been believed that esophageal adenocarcinoma arises in intestinal type mucosa with goblet cells within a columnar-lined esophagus (CLE).

CLE can involve any of three types of epithelium: fundic (gastric), cardial (junctional), and specialized intestinal metaplasia.

The British Society of Gastroenterology does not require confirmation of intestinal metaplasia in biopsies from the esophagus to establish this diagnosis (Gastroenterology TBSO 2005; Playford et al 2006.

In the concept of these guidelines, the presence of IM is thought to be less important for the diagnosis of $\mathrm{BE}$ than the presence of a proper esophageal gland, squamous island, and/or double muscularis mucosa (Takubo et al 1991; Takubo et al 1995; Long et al 1999). The most important rationale behind this view is related to the high rate of sampling errors at index endoscopy. Repeated endoscopy and biopsy are often necessary to confidently detect or exclude the presence of IM. Based on a recent retrospective study, an estimated eight biopsies are necessary for an adequate assessment of the presence of intestinal metaplasia (Harrison et al 2007). Furthermore, a previous study from the UK National Barrett's Oesophagus Registry (UKBOR) has not only confirmed this, but has demonstrated a similar neoplastic risk in patients with columnar metaplasia with and without demonstrable intestinal metaplasia (Vaezi et al 1996; Lieberman et al 1997; Locke et 2003; Smpliner et al 
2002; Watson et al 2005; Shepherd et al 2003; Gatenby et al 2008). The relative risk of adenocarcinoma development in patients with columnar-lined esophagus has been estimated at 5-125 fold higher than of control populations (Van der Veen et al 1989; Bartelsman et al 1992; Iftikar et al 1992; Solaymani-Dodaran et 2004; Anderson et al 2003) with the overall annual adenocarcinoma risk in columnar-lined esophagus at $0.69 \%$ (range 0-3.6\%) per annum (Gatenby et al 2008).

Like the British Society of Gastroenterology, the Japan Esophageal Society defines BE as a CLE with at least one of the following: a proper esophageal gland, squamous island, or double muscularis mucosae (Japan esophageal Society 2009). In a recent review of 141 cases, Takubo et al. demonstrated that more than $70 \%$ of primary esophageal adenocarcinomas were adjacent to cardiac and/or fundic rather than intestinal type mucosa with goblet cells (Takubo et al 2009). This suggests BE might be better defined as the presence of metaplastic columnar-lined esophagus with or without goblet cells, which is in accordance with the British and Japanese definition of BE. As there are still few data on the risk of esophageal adenocarcinoma in CLE lacking IM.

Controversy has surrounded the most appropriate means of reflux control in patients with CLE. While pharmacological acid suppression is the least invasive and most suitable for elderly patients and those with comorbidity, the high incidence of hiatal hernia, lower esophageal sphincter failure, peristaltic impairment, and reflux of duodenal juice renders proton pump inhibitor (PPI) therapy less effective in columnar-lined esophagus than in less severe reflux disease, with up to $40 \%$ still demonstrating pathological acid exposure after receiving up to $80 \mathrm{mg}$ per day of omeprazole (Lundell et al 2001; Katzka et al 1994; Sampliner et al 1994; Ouatu-Lascar et al 1998; Sharma et al 1997). Several series have suggested that fundoplication, by virtue of its ability to correct hiatal hernia, lower esophageal sphincter failure, and reflux of duodenal juice, confers some protection against adenocarcinoma development (Wassnaar et al 2010).

In conclusion BE and CLE may be considered as a synonym.

Progression of BE in this paper is defined as a change in histological findings on biopsy from CLE to any form of dysplasia or an increase in grade of dysplasia. Development of adenocarcinoma is also considered progression of disease. Regression is defined as change from high-grade dysplasia (HGD) to low-grade dysplasia (LGD) or no dysplasia, change from LGD to metaplasia or loss of metaplasia, and change from CLE to complete loss of metaplasia. Shortening of the segment or development of squamous cell islands, although considered by some as regression, usually is not accurately measured and reported, and is therefore, not considered regression in our report. Long-segment BE (LSBE) is defined as > 3 $\mathrm{cm}$, short segment BE (SSBE) is defined as a length $1-3 \mathrm{~cm}$ seen at endoscopy and confirmed by biopsy, ultra-short segment Barrett Esophagus $<1 \mathrm{~cm}$.

The goal of treatment of columnar-lined esophagus is to prevent non-neoplastic complications and development of dysplasia and adenocarcinoma by control of gastroesophageal reflux while maintaining a healed mucosa (Sampliner et al 2002).

Patients with columnar-lined esophagus are among those with the most severe gastroesophageal reflux disease (Winters et al 1987; Avidan et al 2002; Liebermann et al 1997; Locke et al 2003, Csendes et al 2002) and adequate control of reflux is difficult (Katzka et al 1994; Ouatu-Lascar et al 1998; Sharma et al 1997). Medical therapy does not prevent biliary reflux into the esophagus (Vaezi et 1996; Manifold et al 2000), and only surgical 
correction of the defective gastroesophageal sphincter can abolish this (Parilla et al 2003; Watson et al 1997; Zaninotto et al 2002).

Three recent studies have investigated the effect of PPI treatment on the risk of progression of BE to dysplasia or adenocarcinoma (Cooper et al 2006; Hillman et al 2004; Nguyen et al 2009). The results of these controlled studies suggest a protective effect of PPIs in limiting the progression of $\mathrm{BE}$, but they do not eliminate the risk of developing $\mathrm{AC}$.

In the study by Hillman et al, patients were stratified according to delay in starting PPI therapy after the diagnosis of BE was established (Hillman et al 2004). Patients who delayed PPI therapy for $\geq 2$ years after being diagnosed with BE had 5.6 times higher risk of developing low grade dysplasia than patients who used PPI within the first year after diagnosis. Furthermore, patients with $\mathrm{BE}$ had up to a 20 times higher risk of developing high grade dysplasia or adenocarcinoma when PPI therapy was delayed for 2 years after diagnosis of BE. Although this suggests a substantial protective effect, the absolute risk of developing high grade dysplasia or adenocarcinoma was low, 3\%, at a median follow-up of 4.7 years. The small rate of progression of $\mathrm{BE}$ makes it very difficult to show a difference between treatments.

In another study, Cooper et al considered 188 patients with IM who were treated with a PPI, the risk of developing low grade dysplasia within 5 years of the diagnosis of BE was around $2.5 \%$, and the risk of high grade dysplasia or adenocarcinoma was around $2 \%$ while taking PPI therapy (Cooper et al 2006).

However, when following patients for $>5$ years, Nguyen et al recently have found a much higher risk of developing adenocarcinoma (Nguyen et al 2009). They have studied 344 patients diagnosed with BE without dysplasia, with a mean follow-up of 7.6 years. They found that the chance of developing HGD or adenocarcinoma was 7.4\%. Moreover, this risk was even higher when not taking PPIs (14.2\%).

The hypothesis that surgery is superior to medical therapy comes from the assumption that surgery provides better control of GERD than do PPIs, and this should translate into lower progression rates. There have been very few studies comparing medical and surgical therapy.

Gatenby et al published the results of their review of a cohort of 738 patients with BE (Gatenby et al 2009). They compared 41 patients with anti-reflux surgery to 551 treated medically with PPIs, 42 patients treated with $\mathrm{H} 2$ receptor antagonists (H2RAs), 95 patients treated with H2RA followed by PPI and 9 patients with treatment. After a followup of 5 years after medical therapy and 6 years after surgical therapy, there was however a trend toward antireflux surgery being more protective. No patients in the antireflux group developed HGD or AC as compared to $4.3 \%$ in the all-medical therapies group (P = 0.13). There were not enough patients in the surgical arm to determine if this was a significant difference.

Parrilla et al have published the only randomized study comparing 43 patient treated with medical treatment and 58 with antireflux surgery (Parrilla et al 2003). In that study, 101 patients with BE were treated between 1982 and 2000. Medical treatment consisted of H2RA treatment initially and then omeprazole from 1992 onward. Surgery was performed through laparotomy with Nissen fundoplication in 56 patients and a Collis-Nissen procedure in the other two because of short esophagus. All patients had annual clinical, endoscopic and histological follow-up, and patients who had an operation also had a $\mathrm{pH}$ study and manometry at 1 year postoperatively and every 5 years thereafter, or if they presented with 
recurrent GERD symptoms. Mean follow-up was 6 years for the medical therapy group and 7 years for the surgical group. Progression of BE to any dysplasia was found in eight patients $(19 \%)$ in the medical treatment group and in three in the surgical group $(5 \%)$. Two patients in each group progressed to adenocarcinoma, which was confirmed after esophageal resection. Although differences in progression rates between the two groups were not significant according to the authors, when a sub-analysis was performed including only patients in the surgical arm with normal $\mathrm{pH}$, the progression rate dropped to $2 \%$, which was a significantly lower chance of progression of disease than in the medical group. The hypothesis that surgery is superior to medical therapy comes from the assumption that surgery provides better control of GERD than do PPIs, and this should translate into lower progression rates. The control of reflux is essential in preventing progression of disease, is backed up by the fact that, in most studies, the patients with progression after surgical treatment seem to have recurrent reflux. This observation, that control of reflux is essential in preventing progression of disease, is backed up by the fact that, in most studies, the patients with progression after surgical treatment seem to have recurrent reflux (Oelschlager et al 2003; O’Riordan et al 2004; Biertho et al 2007; Lagergren et al 2007; Csendes et al 2004).

Hofstetter et al have published the study with the longest follow-up (Hofstetter et al 2001). They showed results for a series of 97 patients, with complete endoscopic follow-up in 79, at a median of 5 years. No patients developed HGD or adenocarcinoma, but four had progression of metaplasia to LGD (5\%).

Bowers et al, have reported a similar series with a mean follow-up of 4.6 years (Bowers et al 2002). Their 104 patients underwent open or laparoscopic fundoplication. Of these, 64 patients had endoscopic follow-up with biopsy. None of the patients developed HGD or adenocarcinoma. Only one patient had progression to LGD $(1.5 \%)$.

Wassenaar and Oelschlager in a recent review are summarized the result of 11 publications on surgical treatment for $\mathrm{BE}$ that included results on prevention of progression, as well as regression of metaplasia or dysplasia (Wassenaar et al 2010). A total of 551 patients were considered with a median follow up of 3.6 years. The progression rate of metaplasia to dysplasia or adenocarcinoma was $3.4 \%$ and $0.7 \%$ respectively and the regression rate was $30.5 \%$.

Kamolz and colleagues evaluated and compared quality of life data before and after laparoscopic antireflux surgery in GERD patients with and without BE (Kamolz et al 2003). The authors concluded that non-BE patients undergoing laparoscopic antireflux surgery achieved a better quality of life improvement than those patients with BE. The authors compared QoL data of both groups to the mean value of general population. This means that laparoscopic antireflux surgery is able to improve QoL significantly in all GERD patients, with and without BE.

In Conclusion, surgical treatment is able only to control acid and biliopancreatic refluxate, with an improvement of quality of life. A very important point of view is the efficacy of antireflux barrier, infact after surgical treatment, there is also still progression of disease although the risk seems to become very small when this treatment is successful.

The complexity of assessment and management of CLE require a multidisciplinary approach, in regard of diagnosis and strategies of treatment. This is particularly true for surgical therapy, which has to be effective and long lasting; therefore, it should be preferably performed by experienced surgical teams. 


\section{Quality of life after antireflux surgery}

The large success of laparoscopic surgery as an effective treatment of gastroesophageal reflux disease, has established minimal invasive surgery as the gold standard in surgical treatment of this condition. Among antireflux procedures, laparoscopic total fundoplication is the most commonly used, providing excellent symptom relief (Watson et al 1996). Antireflux surgery has been shown to improve not only symptoms, but also quality-of life (QoL) (Velanovich et 1999; Trus et al 1999).

Laparoscopic Nissen fundoplication constructs an antireflux barrier in the cardia region and effectively controls the typical symptoms of gastroesophageal reflux disease in approximately 85-90\% (Bammer et al 2001; Beldi et al 2002; Eubancs et 2000; Carlson et al 2001) of cases at 5 to 10 years follow-up and has low morbidity and mortality rates.

Poor surgical results are caused by mechanical problems or persistence of symptoms (Campos et al 1999; Rice et al 2000).

A proportion of patients have persistent reflux symptoms and require use of proton pump inhibitors despite normal functional studies (Eubancs et al 2000; Khajanchee et al 2002; Galvani et al 2003).

In our study only $5.9 \%$ required PPI post-operatively and the satisfaction rate was $63.8 \%$ at 6 months and $83.3 \%$ at 12 months, with a Johnson\&DeMeester score of 8.05 (IQR: 6.95-10.20) at 6 months and to 7.60 (IQR: 7.60-9.50) at the 12 months follow-up.

After antireflux surgery we observed a significant reduction in both severity and frequency scores of heartburn, epigastric pain, regurgitation, and respiratory symptoms, but an increase of dysphagia for solids and/or liquids. This point of view may affect the improvement of quality of life after Nissen-Rossetti fundoplication. The dysphagia was reported especially during the first 3 postoperative months, and in most cases it could be controlled by diet modifications as it gradually subsided (Loustarinen et al 2001; Mungan et al 1999; Balci et al 2007).

In our series we observed $19.4 \%$ of dysphagia for solids and/or liquids at 1 months postoperatively and only 2 readmissions, with need for endoscopic ballon dilatation in one case, but at 3 months all symptoms had disappeared.

Trus et al reported a significant and durable improvement in all 8 scales of the SF-36 at 6 weeks and 1 year after laparoscopic antireflux surgery (Trus et al 1999).

Amato et al reported that dysphagia for solids and/or liquids was the only significant symptom associated with 3 of 8 scales (physical function, role physical and bodily pain) (Amato et al 2008). A border line association was found between bloating and other 3 of 8 scales (social function, role-emotional and mental health).

Peters et al found no improvement in all 8 scales, with the exception of bodily pain, in 46 patients at a median of 21 months after laparoscopic Nissen fundoplication (Peters et al 1998).

In our series we observed good results of surgical procedures with a DeMeester score after 6 months like 8.05 and after 12 months 7,60 ( $\mathrm{p}<0.0001)$ and an improvement of quality of life measured in all subdomains of SF-36 at 6 months and 12 months.

In our series, also, we evaluated the impact of Nissen-Rossetti fundoplication with GERDHRQL to measure the relation between symptoms and the quality of life of patients before and after surgery.

Balci et al measured QoL with SF-36 and GERD-HRQL in 60 patients at 1 months and 6 months which showed that QoL increased significantly for all their patients after surgery (Balci et al 2007). 
In all subdomains of the SF-36 the patients score increased, showing an improved quality of life in the related aspects of each item and the GERD-HRQL score showed a corresponding increase.

In another study Velanovich compared SF-36 and GERD-HRQL (Velanovich 1998). In that study, multivariate analysis showed that the only significant predictor of patient satisfaction was GERD-HRQL.

Several studies have suggested an influence of psychopathological disorders on the results of laparoscopic fundoplication (Watson et al 1997; Velanovich 2006). Kamolz et al compared the postoperative results of laparoscopic fundoplication in 21 patients with anxiety disorders diagnosed with the International Classification of Diseases 10 (ICD-1) and 21 controls. Although patients with anxiety disorders showed improvements in both their clinical parameters and the postoperative quality of life using the GIQLI questionnaire, such improvements were lower than those seen in control subjects. However, authors stated that these patients should not be excluded from surgery, and that an improvement in panic attacks was seen in one-third of them (Kamolz et al 2001).

These same authors conducted a similar case-control study on 38 patients diagnosed with major depression according to the ICD-10 classification and found that, despite adequate preoperative selection and normalization of functional parameters, these patients showed less symptomatic relief and poorer results in the postoperative GIQLI quality-of-life questionnaire as compared with control cases (Kamolz et al 2003). The same group documented improvement of results and quality of life in patients undergoing surgery for GERD with stress-related symptoms depending on whether or not they had also received psychological therapy (Kamolz et al 2001).

In our study all patients after surgery presented an improvement in quality of life measured by GERD-HRQL, with 25 (IQR 10-35.5) preoperatively, and 7 (IQR 3.5-10.15) at 6 months, and 5 (IQR 2.5-9.5) at 12 months.

In conclusion laparoscopic Nissen-Rossetti fundoplication is a safe and effective surgical procedure for treatment of GERD, generally offering an improvement of quality of life.

Finally, all patients of this series experienced an improvement in their postoperative quality of life.

\section{References}

Allison PR \& Johnstone AS (1953). The oesophagus lined with gastric mucous membrane. Thorax;8:87-101.

Amato G, Limongelli P, Pascariello A, Rossetti G, Del Genio G, Del Genio A et al (2008). Association between persistent symptoms and long-term quality of life after laparoscopic total fundoplication. Am J Sur; 196: 582-586.

Anderson LA, Murray LJ, Murphy S J et al(2003). Mortality in Barrett's oesophagus: results from a population based study. Gut; 52: 1081-1084.

Anvari M \& Allen C (2003). Five-year comprehensive outcomes evaluation in 181 patients after laparoscopic Nissen fundoplication. J Am Coll Surg.;196:51-57

Anvari M \& Allen CJ (1996). Prospective evaluation of dysphagia before and after laparoscopic Nissen fundoplication without routine division of short gastrics. Surg Laparosc Endosc.;6:424-429. 
Attwood SE, Lundell L, Ell C, Galmiche JP, Hatlebakk J, Fiocca R, Lind T, Eklund S, Junghard O; The LOTUS Trial Group (2008). Standardization of Surgical Technique in Antireflux Surgery: The LOTUS Trial Experience. World J Surg.;32:995-998.

Avidan B, Sonnenberg A, Schnell T G, Chejfec G, Metz A \& Sontag S J (2002). Hiatal hernia size, Barrett's length and severity of acid reflux are all risk factors for oesophageal adenocarcinoma. Am J Gastroenterol; 97: 1930-1936.

Bajbouj M, Becker V, Neuber M, et al (2007). Combined pH-metry/impedance monitoring increases the diagnostic yield in patients with atypical gastroesophageal reflux symptoms. Digestion;76(3 4):223-8.

Balci D \& Turkcapar AG (2007). Assessment of Quality of Life after Laparoscopic Nissen Fundoplication in Patients with Gastroesophageal Reflux Disease, World J Surg; 31: 116-121.

Bammer T, Hinder RA, Klaus A \& Klingler PJ (2001). Five- to eight-year outcome of the first laparoscopic Nissen fundoplications. J Gastrointest Surg.;5:42-48.

Barham CP, Gotley DC,Mills A \& Alderson D (1995). Precipitating causes of acid reflux episodes in ambulant patients with gastro-oesophageal reflux disease. Gut;36:50510.

Barrett N (1950). Chronic peptic ulcer of the oesophagus and 'oesophagitis'. Br. J. Surg.;38:175-182.

Bartelsman JFWM, Hameeteman W \& Tytgat GN (1992). Barrett's oesophagus. Eur J Cancer Prev; 1: 323-325.

Beldi G \& Glattli A. (2002) Long-term gastrointestinal symptoms after laparoscopic Nissen fundoplication. Surg Laparosc Endosc Percutan Tech;12:316-319.

Biertho L, Dallemagne B, Dewandre JM, Jehaes C, Markiewicz S, Monami B, Wahlen C \&Weerts J. (2007) Laparoscopic treatment of Barrett's esophagus: long-term results. Surg Endosc; 21: 11-15.

Blomqvist A, Dalenbäck J, Hagedorn C, Lönroth H, Hyltander A \& Lundell L. (2000) Impact of complete gastric fundus mobilization on outcome after laparoscopic total fundoplication. J Gastrointest Surg.;4:493-500.

Bloom S.; McCartney S. \& Langmead L. (2009) The modern investigation and management of gastro-oesophageal reflux disease (GORD). Clinical Medicine, 9, 6: 600-4.

Bonatti H, Achem SR \& Hinder RA. (2008) Impact of changing epidemiology of gastroesophageal reflux disease on its diagnosis and treatment. J Gastrointest Surg.;12:373-381.

Booth MI, Jones L, Stratford J \& Dehn TC. (2002)Results of laparoscopic Nissen fundoplication at 2-8 years after surgery. Br J Surg.;89:476-481.

Booth MI, Stratford J, Jones L \& Dehn TC (2008). Randomized clinical trial of laparoscopic total (Nissen) versus posterior partial (Toupet) fundoplication for gastrooesophageal reflux disease based on preoperative oesophageal manometry. Br J Surg.;95:57-63.

Bowers SP, Mattar SG, Smith CD, Waring JP \& Hunter JG. (2002) Clinical and histologic follow-up after antireflux surgery for Barrett's esophagus. J Gastrointest Surg; 6: 532-538. 
Cameron AJ, Lomboy CT, Pera M \& Carpenter HA (1995). Adenocarcinoma of the esophagogastric junction and Barrett's esophagus. Gastroenterology; 109: 15411546.

Cameron AJ \& Lomboy CT (1992). Barrett's esophagus: Age, prevalence, and extent of columnar epithelium. Gastroenterology;103:1241-1245.

Campos GM, Peters JH, DeMeester TR, Oberg S, Crookes PF, Tan S et al (1999). Multivariate analysis of factors predicting outcome after laparoscopic Nissen fundoplication. J Gastrointest Surg; 3:292-300

Carlson MA \& Frantzides CT (2001). Complications and results of primary minimally invasive antireflux procedures: a review of 10735 reported cases. J Am Coll Surg; 193: 428-39.

Catarci M, Gentileschi P, Papi C, Carrara A, Marrese R, Gaspari AL \& Grassi GB (2004). Evidence-based appraisal of antireflux fundoplication. Ann Surg; 239 :325-337.

Chang E Y, Morris C D, Seltman A K, O'Rourke R W, Chan B K, Hunter J G \& Jobe B A (2007) The effect of antireflux surgery on esophageal carcinogenesis in patients with barrett esophagus: a systematic review. AnnSurg 246:11-21

Chrysos E, Tzortzinis A, Tsiaoussis J, Athanasakis H, Vasssilakis J \& Xynos E (2001). Prospective randomized trial comparing Nissen to Nissen-Rossetti technique for laparoscopic fundoplication. Am J Surg.;182:215-221.

Cooper BT, Chapman W, Neumann CS \& Gearty JC (2006). Continuous treatment of Barrett's oesophagus patients with proton pump inhibitors up to 13 years: observations on regression and cancer incidence. Aliment Pharmacol Ther; 23:727733

Csendes A, Burdiles P, Braghetto I \& Korn O (2004). Adenocarcinoma appearing very late after antireflux surgery for Barrett's esophagus: long-term follow-up, review of the literature, and addition of six patients. J Gastrointest Surg; 8: 434-441.

Csendes A, Smok G, Quiroz J et al (2002). Functional studies in 408 patients with Barrett's esophagus, compared to 174 cases with intestinal metaplasia of the cardia. Am J Gastroenterol;97: 554-560.

Dallemagne B, Weerst JM, Jehaes C, Markiewicz S \& Lombard R (1991). Laparoscopic Nissen Fundoplication: preliminary report. Surg Laparosc Endosc; 1: 138-143.

Dallemagne B, Weerts J, Markiewicz S, Dewandre JM, Wahlen C, Monami B \& Jehaes C (2006). Clinical results of laparoscopic fundoplication at ten years after surgery. Surg Endosc.;20:159-165.

DeMeester TR, Bonavina L \& Albertucci M (1986). Nissen fundoplication for gastroesophageal reflux disease. Evaluation of primary repair in 100 consecutive patients. Ann Surg.;204:9-20.

Dent J, El-Serag HB, Wallander MA \& Johansson S (2005). Epidemiology of gastrooesophageal reflux disease: a systematic review. Gut.;54:710-717.

Dodds WJ, Dent J, Hogan WJ et al (1982). Mechanisms of gastroesophageal reflux in patients with reflux esophagitis. $N$ Engl J Med;307:1547-52.

Donahue PE, Samelson S, Nyhus LM \& Bombeck CT (1985). The floppy Nissen fundoplication. Effective long-term control of pathologic reflux. Arch Surg.;120:663668. 
Engström C, Blomqvist A, Dalenbäck J, Lönroth H, Ruth M \& Lundell L (2004). Mechanical consequences of short gastric vessel division at the time of laparoscopic total fundoplication. J Gastrointest Surg.;8:442-447.

Eubanks TR, Omelanczuk P, Richards C, Pohl D \& Pellegrini CA (2000). Outcomes of laparoscopic antireflux procedures. Am J Surg; 179: 391-5.

Farrell TM, Archer SB, Galloway KD, Branum GD, Smith CD \& Hunter JG (2000). Heartburn is more likely to recur after Toupet fundoplication than Nissen fundoplication. Am Surg.;66:229-236.

Fass R, Quan SF, O'Connor GT, Ervin A \& Iber C (2005). Predictors of heartburn during sleep in a large prospective cohort study. Chest;127:1658-66.

Fein M, Bueter M, Thalheimer A, Pachmayr V, Heimbucher J, Freys SM \& Fuchs KH (2008). Ten-year outcome of laparoscopic antireflux surgery. J Gastrointest Surg.;12:18931899.

Fernando HC, Luketich JD, Christie NA, Ikramuddin S \& Schauer PR (2002). Outcomes of laparoscopic Toupet compared to laparoscopic Nissen fundoplication. Surg Endosc.;16:905-8.

Fornari F \& Sifrim D (2007). Gastroesophageal reflux and atypical symptoms: the role of impedance-pH monitoring. Digestion;76(3-4):221-2.

Galvani C, Fisichella PM, Gorodner MV, Perretta S \& Patti MG (2003). symptoms are a poor indicator of reflux status after fundoplication for gastroesophageal reflux disease. Role of esophageal functions test. Arch Surg; 138:514-9

Gastroenterology TBSO (2005). Guidelines for the diagnosis and management of Barrett's columnar-lined oesophagus . cited; Available from: http:/ /www.bsg.org.uk.

Gatenby PA, Caygill CPJ, Ramus JR, Charlett A \& Watson A (2008). Barrett's columnar-lined oesophagus: demographic associations and adenocarcinoma risk. Dig Dis Sci; 53: 1175-1185.

Gatenby PA, Ramus JR, Caygill CPJ, Shepherd NA, Watson A (2008). The relevance of detection of intestinal metaplasia in columnar-lined esophagus. Scand J Gastroenterol;43:524-530.

Gatenby PA, Ramus JR, Caygill CP, Charlett A, Winslet MC \& Watson A (2009). Treatment modality and risk of development of dysplasia and adenocarcinoma in columnarlined esophagus. Dis Esophagus; 22: 133-142.

Guérin E, Bétroune K, Closset J, Mehdi A, Lefèbvre JC, Houben JJ, Gelin M, Vaneukem P \& El Nakadi I (2007). Nissen versus Toupet fundoplication: results of a randomized and multicenter trial. Surg Endosc;21:1985-1990.

Hampel H, Abraham NS \& El-Serag HB (2005). Meta-analysis: obesity and the risk for gastroesophageal reflux disease and its complications. Ann Intern Med;143:199-211.

Harrison R, Perry I, Haddadin W et al (2007). Detection of intestinal metaplasia in Barrett's esophagus: An observational comparator study suggests the need for a minimum of eight biopsies. Am. J. Gastroenterol.;102:1154-1161.

Hillman LC, Chiragakis L, Shadbolt B, Kaye GL \& Clarke AC (2004). Proton-pump inhibitor therapy and the development of dysplasia in patients with Barrett's oesophagus. Med J Aust;180: 387-391

Hirota WK, Loughney TM, Lazas DJ, Maydonovitch CL, Rholl V \& Wong RK (1999). Specialized intestinal metaplasia, dysplasia, and cancer of the esophagus and 
esophagogastric junction: Prevalence and clinical data. Gastroenterology;116:277285.

Hofstetter WL, Peters JH, DeMeester TR, Hagen JA, De-Meester SR, Crookes PF, Tsai P, Banki F \& Bremner CG (2001). Longterm outcome of antireflux surgery in patients with Barrett's esophagus. Ann Surg; 234: 532-538.

Horvath KD, Jobe BA, Herron DM \& Swanstrom LL (1999). Laparoscopic Toupet fundoplication is an inadequate procedure for patients with severe reflux disease. J Gastrointest Surg.;3:583-591.

Hüttl TP, Hohle M, Wichmann MW, Jauch KW \& Meyer G (2005). Techniques and results of laparoscopic antireflux surgery in Germany. Surg Endosc.;19:1579-87.

Iftikar SY, James PD, Steele RJC, Hardcastle JD \& Atkinson M (1992). Length of Barrett's oesophagus: an important factor in the development of dysplasia and adenocarcinoma. Gut; 33:1155-1158.

Japan Esophageal Society (2009). Japanese Classification of Esophageal Cancer, tenth edition: Part I. Esophagus ;6:1-26.

Jobe BA, Wallace J, Hansen PD \& Swanstrom LL (1997). Evaluation of laparoscopic Toupet fundoplication as a primary repair for all patients with medically resistant gastroesophageal reflux. Surg Endosc.;11:1080-1083.

Johnson LF (1980). 24-hour pH monitoring in the study of gastroesophageal reflux. J Clin Gastroenterol;2:387.

Jones RH, Hungrin ADS \& Phillips J (1995). Gastroesophageal reflux disease in primary care in Europe: clinical presentation and endoscopic findings. Eur J Gen Pract;1:149-54.

Kahrilas PJ, Dodds WJ, Hogan WJ et al (1986). Esophageal peristaltic dysfunction in peptic esophagitis. Gastroenterology;91:897-904.

Kahrilas PJ, Dodds WJ, Hogan WJ et al (1986). Esophageal peristaltic dysfunction in peptic esophagitis. Gastroenterology;91:897-904.

Kalmoz T, Bammer T, Granderath FA \& Pointer R (2001). Laparoscopic antireflux surgery in gastroesophageal reflux disease patients with concomitant anxiety disorders. Dig Liver Dis; 33: 659-664.

Kalmoz T, Granderath FA, Bammer T, Pasiut M (2001) Pointner R. Psycological intervention influences the outcome of laparoscopic antireflux surgery in patients with stressrelated symptoms of gastroesophageal reflux disease. Scand J Gastroenterol ; 36: 800-805.

Kalmoz T, Granderath FA \& Pointner R (2003). Does major depression in patients with gastroesophageal reflux affects the outcome of laparoscopic antireflux surgery? Surg Endosc; 17:55-60.

Kamolz T, Granderath F \& Pointner R (2003). Laparoscopic antireflux surgery: diseaserelated quality of life assessment before and after surgery in GERD patients with and without Barrett's esophagus. Surg Endosc.;17:880-885.

Kamolz T, Granderath FA, Bammer T, Wykypiel H Jr \& Pointner R (2002). "Floppy" Nissen vs. Toupet laparoscopic fundoplication: quality of life assessment in a 5-year follow-up (part 2). Endoscopy.;34:917-922.

Katzka D A \& Castell D O (1994). Successful elimination of reflux symptoms does not insure adequate control of acid reflux in patients with Barrett's esophagus. Am J Gastroenterol; 89:989-991. 
Kelly JJ, Watson DI, Chin KF, Devitt PG \& Game PA (2007) Jamieson GG. Laparoscopic Nissen fundoplication: clinical outcomes at 10 years. J Am Coll Surg.;205:570-575.

Khajanchee YS. O'Rourke RW, Lockhart B, Patterson EJ, Hansen PD \& Swanstrom LL (2002). Postopearive symptoms and failure after antireflux surgery. Arch Surg;137:1008-14.

Kösek V, Wykypiel H, Weiss H, Höller E, Wetscher G, Margreiter R \& Klaus A (2009). Division of the short gastric vessels during laparoscopic Nissen fundoplication: clinical and functional outcome during long-term follow-up in a prospectively randomized trial. Surg Endosc. Oct;23:2208-13.

Laffullarde T, Watson DI, Jamieson GG, Myers JC, Game PA \& Devitt PG (2001). Laparoscopic Nissen Fundoplication: five-year results and beyond. Arch Surg; 136: 180-184.

Lagergren J, Bergstrom R, Lindgren A \& Nyren O (1999) Symptomatic gastroesophageal reflux as a risk factor for esophageal adenocarcinoma. N Engl J Med 340:825-831

Lagergren J \& Viklund P (2007). Is esophageal adenocarcinoma occurring late after antireflux surgery due to persistent postoperative reflux? World J Surg; 31: 465-469

Laws HL, Clements RH \& Swillie CM (1997). A randomized, prospective comparison of the Nissen fundoplication versus the Toupet fundoplication for gastroesophageal reflux disease. Ann Surg.;225:647-653.

Leggett PL, Bissell CD, Churchman-Winn R \& Ahn C (2000). A comparison of laparoscopic Nissen fundoplication and Rossetti's modification in 239 patients. Surg Endosc.;14:473-477.

Lieberman D A, Oehlke M, Helfand M \& the GORGE Consortium (1997). Risk factors for Barrett's esophagus in community-based practice. Am J Gastroenterol; 92:12931297.

Locke G R, Zinsmeister A R \& Talley N J (2003). Can symptoms predict endoscopic findings in GERD? Gastrointest Endosc; 58: 661-670.

Long JD \& Orlando RC (1999). Esophageal submucosal glands: Structure and function. Am. J. Gastroenterol.;94:2818-2824.

Loustarinen M, Vurtanen J, Koskinen M, Matikainen M \& Isolauri J (2001). Dysphagia and oesophageal clearance after laparoscopic versus open Nissen fundoplication. A randomized, prospective trial. Scand J Gastroenterol;36:565-571.

Loustarinen ME \& Isolauri JO (1999). Randomized trial to study the effect of fundic mobilization on long-term results of Nissen fundoplication. Br J Surg.;86:614-618.

Lundell L, Miettinen P, Myrvold HE, Hatlebakk JG, Wallin L, Malm A, Sutherland I, Walan A \& Nordic GORD Study Group (2007). Seven-year follow-up of a randomized clinical trial comparing proton-pump inhibition with surgical therapy for reflux oesophagitis Br J Surg.;94:198-203.

Lundell L, Miettinen P, Myrvold HE, Pederson SA, Liedman B, Hatlebakk JG, Julkonen R, Levander K, Carlsson J, Lamm M \& Wiklund I (2001). Continued (5-year) follow-up of a randomized clinical study comparing antireflux surgery and omeprazole in gastroesophageal reflux disease. J Am Coll Surg ; 192: 172-179; discussion 179:181.

Manifold D K, Marshall R E K, Anggiansah A \& Owen W J (2000). Effect of omeprazole on antral duodenogastric reflux in Barrett oesophagus. Scand J Gastroenterol; 8: 796801. 
Mardani J, Lundell L, Lönroth H, Dalenbäck J \& Engström C (2009). Ten-year results of a randomized clinical trial of laparoscopic total fundoplication with or without division of the short gastric vessels. Br J Surg.;96:61-65.

McKenzie D, Grayson T \& Polk HC Jr (1996). The impact of omeprazole and laparoscopy upon hiatal hernia and reflux esophagitis. J Am Coll Surg; 183: 413-418.

Morgenthal CB, Shane MD, Stival A, Gletsu N, Milam G, Swafford V, Hunter JG \& Smith CD (2007). The durability of laparoscopic Nissen fundoplication: 11-year outcomes. J Gastrointest Surg.;11:693-700.

Mungan Z, Demir K, Onuk MD, Göral V, Boztaş G, Beşışık F al (1999). Characteristics of gastroesophageal reflux disease in our country. Turk J Gastroenterol;10:101-106.

Naef AP, Savary M \& Ozzello L (1975). Columnar-lined lower esophagus: an acquired lesion with malignant predisposition. Report on 140 cases of Barrett's esophagus with 12 adenocarcinomas. J. Thorac. Cardiovasc. Surg.;70:826-835.

Nguyen DM, El-Serag HB, Henderson L, Stein D, Bhattacharyya A \& Sampliner RE (2009). Medication usage and the risk of neoplasia in patients with Barrett's esophagus. Clin Gastroenterol Hepatol; 7: 1299-1304.

O'Boyle CJ, Watson DI, Jamieson GG, Myers JC, Game PA \& Devitt PG (2002). Division of short gastric vessels at laparoscopic nissen fundoplication: a prospective doubleblind randomized trial with 5-year follow-up. Ann Surg;235:165-170.

Oelschlager B K, Eubanks T R, Oleynikov D, Pope C \& Pellegrini C A (2002) Symptomatic and physiologic outcomes after operative treatment for extraesophageal reflux. Surg Endosc 16:1032-1036

Oelschlager BK, Barreca M, Chang L, Oleynikov D \& Pellegrini CA (2003). Clinical and pathologic response of Barrett's esophagus to laparoscopic antireflux surgery. Ann Surg; 238: 458-464.

Oelschlager BK, Quiroga E, Parra JD, Cahill M, Polissar N \& Pellegrini C A (2008). Longterm outcomes after laparoscopic antireflux surgery. Am J Gastroenterol.;103:280287.

O'Riordan JM, Byrne PJ, Ravi N, Keeling PW \& Reynolds JV (2004). Long-term clinical and pathologic response of Barrett's esophagus after antireflux surgery. Am J Surg; 188: 27-33.

Ouatu-Lascar R \& Triadafilopoulos G (1998). Complete elimination of reflux symptoms does not guarantee normalisation of intraesophageal acid reflux in patients with Barrett's esophagus. Am J Gastroenterol; 93: 711-716.

Pandolfino JE, El-Serag HB, Zhang Q et al (2006). Obesity: a challenge to esophagogastric junction integrity. Gastroenterology;130:639-49.

Pandolfino JE, Shi G, Trueworthy B \& Kahrilas PJ (2003). Esophagogastric junction opening during relaxation distinguishes nonhernia reflux patients, hernia patients, and normal subjects. Gastroenterology;125:1018-24

Paraf F, Flejou JF, Pignon JP, Fekete F \& Potet F (1995). Surgical pathology of adenocarcinoma arising in Barrett's esophagus. Analysis of 67 cases. Am. J. Surg. Pathol.;19:183-191.

Parker SL, Tong T, Bolden S \& Wingo PA (1997). Cancer statistics, 1997. CA Cancer J. Clin.;47:5-27. 
Parrilla P, Martínez de Haro LF, Ortiz A, Munitiz V, Molina J, Bermejo J \& Canteras M (2003). Long-term results of a randomized prospective study comparing medical and surgical treatment of Barrett's esophagus. Ann Surg; 237: 291-298.

Pessaux P, Arnaud JP, Delattre JF, Meyer C, Baulieux J \& Mosnier H (2005). Laparoscopic antireflux surgery: five-year results and beyond in 1340 patients. Arch Surg.;140:946-951.

Peters JH, DeMeester TR, Crookes P, Oberg S, de Vos Shoop M, Hagen JA et al (1998). The treatment of gastroesophageal reflux disease with laparoscopic Nissen fundoplication: prospective evaluation of 100 patients with "typical" symptoms. Ann Surg;228:40-50.

Peters MJ, Mukhtar A, Yunus RM, Khan S, Pappalardo J, Memon B \& Memon MA (2009). Meta-analysis of randomized clinical trials comparing open and laparoscopic antireflux surgery. Am J Gastroenterol;104:1548-61.

Playford RJ (2006). New British Society of Gastroenterology (BSG) guidelines for the diagnosis and management of Barrett's oesophagus . Gut; 55:442.

Pohl H \& Welch HG (2005). The role of overdiagnosis and reclassification in the marked increase of esophageal adenocarcinoma incidence. J. Natl. Cancer Inst.; 97:142-146.

Rakita S, Villadolid D, Thomas A, Bloomston M, Albrink M, Goldin S \& Rosemurgy A (2006) Laparoscopic Nissen fundoplication offers high patient satisfaction with relief of extraesophageal symptoms of gastroesophageal reflux disease. Am Surg 72:207212.

Rice T W (2000). Why antireflux surgery fails? Dig Dis;18:43-7.

Rice T. W. \& Blackstone E. H (2008). Surgical Management of Gastroesophageal Reflux Disease Gastroenterol Clin N Am 37: 901-919.

Roberts KE, Duffy AJ \& Bell RL (2006). Controversies in the treatment of gastroesophageal reflux and achalasia. World J Gastroenterol.;12:3155-3161.

Rossetti M \& Hell K (1977). Fundoplication for the treatment of gastroesophageal reflux in hiatal hernia. World J Surg.;1:439-443.

Rossi M, Barreca M, de Bortoli N, Renzi C, Santi S, Gennai A, Bellini M, Costa F, Conio M \& Marchi S (2006). Efficacy of Nissen fundoplication versus medical therapy in the regression of low-grade dysplasia in patients with Barrett esophagus: a prospective study. Ann Surg 243:58-63.

Salminen PT, Hiekkanen HI, Rantala AP \& Ovaska JT (2007). Comparison of long-term outcome of laparoscopic and conventional nissen fundoplication: a prospective randomized study with an 11-year follow-up. Ann Surg.;246:201-206.

Sampliner R E (1994). Effect of up to 3 years of high-dose lansoprazole on Barrett's esophagus. Am J Gastroenterol; 89:1844-1848.

Sampliner RE (2002). The Practice Parameters Committee of the American College of Gastroenterology. Updated guidelines for the diagnosis, surveillance, and therapy of Barrett's esophagus. Am J Gastroenterol.; 97:1888-95.

Sato K, Awad ZT, Filipi CJ, Selima MA, Cummings JE, Fenton SJ \& Hinder RA (2002). Causes of long-term dysphagia after laparoscopic Nissen fundoplication. JSLS.;6:35-40. 
Sgromo B, Irvine LA, Cuschieri A \& Shimi SM (2008). Long-term comparative outcome between laparoscopic total Nissen and Toupet fundoplication: Symptomatic relief, patient satisfaction and quality of life. Surg Endosc.;22:1048-1053.

Sharma P, Sampliner R E \& Camargo E (1997). Normalisation of esophageal pH with highdose proton pump inhibitor therapy does not result in regression of Barrett's esophagus. Am J Gastroenterol.; 92:582-585.

Shepherd NA (2003). Barrett's esophagus: its pathology and neoplastic complications. Esophagus; 1:17-29.

Smith RR, Hamilton SR, Boitnott JK \& Rogers EL (1984). The spectrum of carcinoma arising in Barrett's esophagus.A clinicopathologic study of 26 patients. Am. J. Surg. Pathol.;8:563-573.

Society of American Gastrointestinal and Endoscopic Surgeons (2010). Guidelines for surgical treatment of gastro-oesophageal reflux disease (GERD). Avaible at: http://www.sages.org/publication/id/22/

Solaymani-Dodaran M, Logan RFA, West J, Card T \& Coupland C (2004). Risk of oesophageal cancer in Barrett's oesophagus and gastro-oesophageal reflux. Gut; 53: 1070-1074.

Spechler S J \& Goyal R K (1996) The columnar-lined esophagus, intestinal metaplasia, and Norman Barrett. Gastroenterology 110:614-621

Spechler SJ, Lee E, Ahnen D, Goyal RK, Hirano I, Ramirez F, Raufman JP, Sampliner R, Shnell T, Sontag S, Vlahcevic ZR, Young R \& Williford W (2001). Long-term outcome of medical and surgical therapies for gastroesophageal reflux disease: follow-up of a randomized controlled trial. JAMA; 285: 2331-2338.

Stanciu C \& Bennett JR (1974). Alginate/antacid in the reduction of gastro-oessophageal reflux. Lancet;I:109-111.

Strate U, Emmermann A, Fibbe C, Layer P \& Zornig C (2008). Laparoscopic fundoplication: Nissen versus Toupet two-year outcome of a prospective randomized study of 200 patients regarding preoperative esophageal motility. Surg Endosc.;22:21-30.

Takubo K, Aida J, Naomoto Y et al (2009). Cardiac rather than intestinal-type background in endoscopic resection specimens of minute Barrett adenocarcinoma. Hum. Pathol.;40: 65-74.

Takubo K, Nixon JM \& Jass JR (1995). Ducts of esophageal glands proper and paneth cells in Barrett's esophagus: Frequency in biopsy specimens. Pathology;27:315-317.

Takubo K, Sasajima K, Yamashita K, Tanaka Y \& Fujita K (1991). Double muscularis mucosae in Barrett's esophagus. Hum. Pathol.;22:1158-1161.

Trus TL, Laycock WS, Waring JP, Branum GD \& Hunter JG (1999). Improvement in qualityof-life measures after laparoscopic antireflux surgery. Ann. Surg.;229:331-336.

Vaezi MF \& Richter JE (1996). Role of acid and duodenogastroesophageal reflux in gastroesophageal reflux disease. Gastroenterology.; 111:1192-1199.

Vakil N, van Zanten SV, Kahrilas P, Dent J \& Jones R (2006). The Montreal definition and classification of gastroesophageal reflux disease: a global evidence-based consensus. Am J Gastroenterol.;101:1900-1920.

Van der Veen AH, Blankenstein JD \& van Blankenstein M (1989). Adenocarcinoma in Barrett's oesophagus: an overrated risk. Gut; 30: 14-18. 
Velanovich V (1998). Comparison of generic (SF-36) versus disease specific (GERD-HRQL) quality of life scales for gastroesophageal reflux disease. J Gastrointest Surg.; 2:141145.

Velanovich V (1999). Comparison of symptomatic and quality-of-life outcomes of laparoscopic and open antireflux surgery. Surgery.; 126:782-789.

Velanovich V (2006). Nonsurgical factors affecting symptomatic outcomes of antireflux surgery. Dis Esophagus. ;19: 1-4.

Wang KK \& Sampliner RE (2008). Updated guidelines 2008 for the diagnosis, surveillance and therapy of Barrett's esophagus. Am. J. Gastroenterol.; 103:788-797.

Ware JE \& Sherbourne CD (1992). The MOS 36-item short-form health survey (SF-36). I. Conceptual framework and item selection. Med Care; 30:473-83

Wassenaar EB \& Oelschlager BK (2010). Effect of medical and surgical treatment of Barrett's metaplasia. World J Gastroenterol.;16:3773-3779.

Watson A, Heading RC \& Shepherd NA (2005). Guidelines for the diagnosis and management of Barrett's columnar-lined oesophagus: a report of the working party of the British Society of gastroenterology. British Society of Gastroenterology.; London, UK; $1-42$.

Watson D I, Pike G K, Baigrie R J et al (1997). Prospective doubleblind randomized trial of laparoscopic Nissen fundoplication with division and without division of short gastric vessels. Ann Surg.; 226: 642-652.

Watson DI, Chan AS, Myers JC \& Jamieson GG (1997). Illness behaviour influences the outcome of laparoscopic antireflux surgery. J Am Coll Surg.; 184:44-48.

Watson DI \& de Beaux AC (2001). Complications of laparoscopic antireflux surgery. Surg Endosc.;15:344-52.

Watson DI, Jamieson GG, Baigrie RJ, Mathew G, Devitt PG, Game PA, et al (1996). Laparoscopic surgery for gastroesophageal reflux : beyond the learning curve. $\mathrm{Br} \mathrm{J}$ Surg; 83:1284-1287.

Watson DI, Jamieson GG, Devitt PG, Matthew G, Britten-Jones RE, Game PA \& Williams RS (1995). Changing strategies in the performance of laparoscopic Nissen fundoplication as a result of experience with 230 operations. Surg Endosc.;9:961-6.

Watson DI, Pike GK, Baigrie RJ, Mathew G, Devitt PG, Britten-Jones R \& Jamieson GG (1997). Prospective double-blind randomized trial of laparoscopic Nissen fundoplication with division and without division of short gastric vessels. Ann Surg.;226:642-652.

Winters C Jr, Spurling TJ, Chobanian SJ et al (1987). Barrett's esophagus. A prevalent, occult complication of gastroesophageal reflux disease. Gastroenterology.;92:118-124.

Yang H, Watson DI, Lally CJ, Devitt PG, Game PA \& Jamieson GG (2008). Randomized trial of division versus nondivision of the short gastric vessels during laparoscopic Nissen fundoplication: 10-year outcomes. Ann Surg.;247:38-42.

Zagari RM, Fuccio L,Wallander MA et al (2008). Gastro-oesophageal reflux symptoms, oesophagitis and Barrett's oesophagus in the general opoulation: the LoianoMonghidoro study. Gut;57:1354-9.

Zaninotto G, Portale G, Costantini M, Rizzetto C, Guirroli E, Ceolin M, Salvador R, Rampado S, Prandin O, Ruol A \& Ancona E (2007). Long-term results (6-10 years) of laparoscopic fundoplication. J Gastrointest Surg.;11:1138-1145. 
Zaninotto G, Portale G, Parenti A, Lanza C, Costantini M, Molena D, Ruol A, Battaglia G, Costantino M, Epifani M \& Nicoletti L (2002). Role of acid and bile reflux in development of specialised intestinal metaplasia in distal oesophagus. Dig Liver Dis.;3:251-257.

Zügel N, Jung C, Bruer C, Sommer P \& Breitschaft K (2002). A comparison of laparoscopic Toupet versus Nissen fundoplication in gastroesophageal reflux disease. Langenbecks Arch Surg.;386:494-498. 


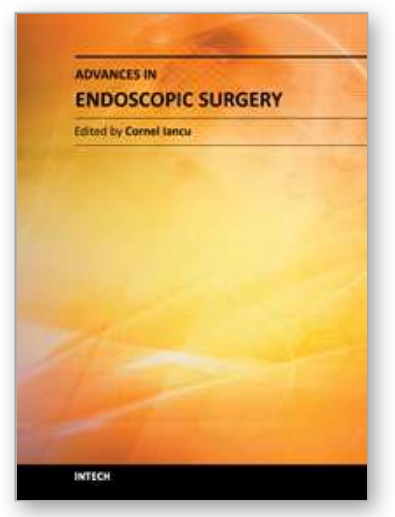

\author{
Advances in Endoscopic Surgery \\ Edited by Prof. Cornel lancu
}

ISBN 978-953-307-717-8

Hard cover, 444 pages

Publisher InTech

Published online 25, November, 2011

Published in print edition November, 2011

Surgeons from various domains have become fascinated by endoscopy with its very low complications rates, high diagnostic yields and the possibility to perform a large variety of therapeutic procedures. Therefore during the last 30 years, the number and diversity of surgical endoscopic procedures has advanced with many new methods for both diagnoses and treatment, and these achievements are presented in this book. Contributing to the development of endoscopic surgery from all over the world, this is a modern, educational, and engrossing publication precisely presenting the most recent development in the field. New technologies are described in detail and all aspects of both standard and advanced endoscopic maneuvers applied in gastroenterology, urogynecology, otorhinolaryngology, pediatrics and neurology are presented. The intended audience for this book includes surgeons from various specialities, radiologists, internists, and subspecialists.

\title{
How to reference
}

In order to correctly reference this scholarly work, feel free to copy and paste the following:

Filippo Tosato, Salvatore Marano, Stefano Mattacchione, Barbara Luongo, Giulia Paltrinieri, Valentina Mingarelli and Leoluca Vasapollo (2011). Surgical Treatment of Gastroesophageal Reflux Disease, Advances in Endoscopic Surgery, Prof. Cornel lancu (Ed.), ISBN: 978-953-307-717-8, InTech, Available from: http://www.intechopen.com/books/advances-in-endoscopic-surgery/surgical-treatment-of-gastroesophagealreflux-disease

\section{INTECH}

open science | open minds

\author{
InTech Europe \\ University Campus STeP Ri \\ Slavka Krautzeka 83/A \\ 51000 Rijeka, Croatia \\ Phone: +385 (51) 770447 \\ Fax: +385 (51) 686166 \\ www.intechopen.com
}

\author{
InTech China \\ Unit 405, Office Block, Hotel Equatorial Shanghai \\ No.65, Yan An Road (West), Shanghai, 200040, China \\ 中国上海市延安西路65号上海国际贵都大饭店办公楼 405 单元 \\ Phone: +86-21-62489820 \\ Fax: $+86-21-62489821$
}


(C) 2011 The Author(s). Licensee IntechOpen. This is an open access article distributed under the terms of the Creative Commons Attribution 3.0 License, which permits unrestricted use, distribution, and reproduction in any medium, provided the original work is properly cited. 